\title{
El Sitio Loma Ruiz 1: Estrategias tecnológicas líticas durante el Holoceno Tardío Inicial en la transición Pampeano-Patagónica oriental
}

RMA

Arqueología

\author{
Gabriela Armentano*, Gustavo Martínez** y Cecilia Landini***
}

*INCUAPA-CONICET. Depto. de Arqueología Facultad de Ciencias Sociales, Olavarría. Universidad Nacional del Centro de la Provincia de Buenos Aires, Argentina. E-mail: garmenta@soc.unicen.edu.ar **INCUAPA-CONICET. Depto. de Arqueología Facultad de Ciencias Sociales, Olavarría. Universidad Nacional del Centro de la Provincia de Buenos Aires, Argentina. E-mail: gmartine@soc. unicen.edu.ar ${ }^{* * *}$ División de Arqueología, Facultad de Ciencias Naturales y Museo.

Universidad Nacional de La Plata, Argentina. clandini@fcnym.unlp.edu.ar

\begin{abstract}
Resumen
El sitio Loma Ruiz 1 se encuentra emplazado en el curso inferior del río Colorado, en el área de transición PampeanoPatagónica oriental. El conjunto arqueológico datado en ca. 1900-1600 años $C^{14}$ AP se compone de materiales líticos, faunísticos y cerámicos recuperados tanto en posición superficial como estratigráfica. Los objetivos de este trabajo son discutir las características tecno-tipológicas del conjunto lítico, las estrategias de adquisición y gestión de materias primas líticas, las intenciones y técnicas de talla, los métodos de débitage y façonnage 1 , las chaînes opératoires ${ }^{2}$ y la diversidad artefactual registrada. Asimismo, se discute cómo se ajustan los resultados obtenidos al modelo tecnológico areal existente. Estos indican estrategias diferenciales en la explotación de rocas según su origen (local, areal o extra-areal). Las técnicas de talla, los métodos de débitage, las características de los artefactos, sumados a la fragmentación en el espacio y tiempo de las chaînes opératoires reflejan distintos grados de planificación y estrategias de producción artefactual acordes con la procedencia de las rocas empleadas. La presencia de artefactos confeccionados sobre materias primas de la subregión Pampa Húmeda y, posiblemente, de Norpatagonia, indica la circulación de instrumentos en estado avanzado de confección durante el Holoceno tardío inicial.
\end{abstract}

Palabras clave: Curso inferior del río Colorado; Holoceno Tardío inicial. Estrategias tecnológicas. Materias primas. Chaînes opératoires

The Loma Ruiz 1 site: Lithic technological strategies during the Initial Late Holocene in eastern Pampa-Patagonia transition.

\begin{abstract}
The Loma Ruiz 1 site (Buenos Aires Province) is located in the lower stream of the Colorado river, in the eastern Pampean-Patagonian transition. The archaeological assemblage recovered is composed of lithic, faunal and pottery remains, both in surface and in stratigraphic position. The archaeological component defined in the latter is dated at ca. 1900-1600 ${ }^{14} \mathrm{C}$ years BP. The objectives of this paper are to discuss the techno-typological characteristics of the lithic assemblage, the acquisition and management strategies of lithic raw materials, the purposes involved and employed knapping techniques, the débitage and façonnage methods, chaînes opératoires and diversity of tool categories. These results indicate strategies of differential exploitation of particular rocks according to their origin (local, areal and extra-areal). Knapping techniques, débitage methods and tool characteristics, as well as the differences in the space-time fragmentation of the chaînes opératoires related to raw material provenience, revealed differences in planning and tool production strategies. The presence of artifacts made of raw materials from the Humid Pampa sub-region and, possibly, from Northern Patagonia, indicates the circulation of tools in an advanced stage of preparation for the Initial Late Holocene (ca. 3000-1000 years BP). On the basis of these results, the already proposed lithic technological model for the lower stream of the Colorado river is evaluated.
\end{abstract}

Keywords: Lower Stream of the Colorado river. Initial Late Holocene. Technological strategies. Raw materials. Chaînes opératoires.

Recibido 09-08-2012. Recibido con correcciones 12-03-2013. Aceptado 25-06/-013 


\section{Introducción: Antecedentes del sitio y objetivos}

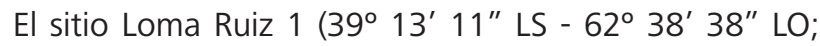
Partido de Villarino, Provincia de Buenos Aires) se encuentra emplazado en una zona baja, dentro de uno de los corredores eólicos del área y en inmediaciones de dos lagunas que ofrecen una alternativa de agua potable en varios kilómetros a la redonda. El sitio se encuentra a ca. $35 \mathrm{~km}$ al $\mathrm{N}$ del río Colorado y a ca. $30 \mathrm{~km}$ de la costa atlántica (Figura 1). En el año 2001 se realizaron tareas de campo que consistieron en transectas, sondeos y excavaciones. Diversos materiales (líticos, cerámicos, óseos) fueron recuperados a partir de estos trabajos, en los cuales además se delinearon los principales aspectos estratigráficos del sitio. Los primeros reportes sistemáticos sobre el mismo se refirieron al contexto general, estratigrafía, cronología y zooarqueología (Martínez 2004; Martínez et al. 2004; Stoessel 2007). Sobre esta base se desarrollaron estudios más sistemáticos y de detalle que incluyeron a algunos de los aspectos ya mencionados, así como la exploración de nuevas líneas de evidencia. En este sentido, Stoessel (2012) re-analizó la colección faunística perteneciente a especies de tamaño grande concluyendo que el sitio se caracteriza por una baja densidad de restos faunísticos y un escaso número de especies representadas, donde el guanaco es el único taxón que muestra evidencias de explotación y consumo. Stoessel (2012) también analizó los índices de fractura ósea del conjunto faunístico concluyendo que los mismos indican actividades relacionadas al consumo de médula y, posiblemente, grasa ósea. Las carcasas de guanacos habrían entrado incompletas al sitio y habrían sido parte de actividades de procesamiento secundario y consumo. Los vertebrados de tamaño pequeño fueron estudiados por Alcaráz (2012), quien determinó que los roedores dominan el conjunto, secundados por aves, anuros, ofidios, dasipódidos, marsupiales y carnívoros. Estas especies ingresaron al depósito naturalmente por causas eto-ecológicas y depredacionales. El único taxón que eventualmente podría haber ingresado por causas antrópicas es el peludo, pero las evidencias no son aún suficientes para afirmarlo. Los análisis tafonómicos realizados por estas dos autoras son coincidentes e indican que la acción de raíces, el deterioro químico y la tinción por óxido de manganeso fueron las principales modificaciones registradas sobre las superficies óseas. Las tendencias de estos análisis permiten proponer que los procesos postdepositacionales más importantes operaron in situ (ver debajo).

Con relación a la cerámica recuperada del sitio, se registraron partes de cuerpo y, en menor medida bordes. Predominan las superficies alisadas y en todos los fragmentos se observaron inclusiones no plásticas.

Con respecto a las técnicas decorativas, la mayor parte de los fragmentos presentan motivos realizados por impresión, implicando la presión y el arrastre con instrumentos sobre las superficies a decorar. Con menor frecuencia se registran también pintura e incisión de surco rítmico. Se observaron sustancias adheridas e impregnaciones en fragmentos sin decoración. La cerámica fue asociada a contextos de uso culinarios (Martínez et al. 2011). La información obtenida de estas líneas, así como la proveniente de los artefactos líticos que se presenta en este trabajo, permitió proponer que el sitio Loma Ruiz 1 sería el producto de bases residenciales, cuyas ocupaciones habrían sido breves o efímeras ubicadas

Figura 1.- Ubicacion del sitio Loma Ruiz 1, en el curso inferior del río Colorado. Se destacan los afloramientos de materias primas extra-areales en las provincias de Buenos Aires, Río Negro y Neuquén.

Figure 1.- Location of Loma Ruiz 1 site along the lower basin of the Colorado river. Extra-areal lithic raw material outcrops in the provinces of Buenos Aires, Rio Negro and Neuquen are highlighted. 
temporalmente en el Holoceno tardío inicial (1900-1600 años $C^{14} \mathrm{AP}$; ver cronología debajo).

Armentano (2012) incluyó al sitio Loma Ruiz 1 como parte de su análisis tecno-morfológico y de chaînes opératoires de algunos sitios del curso inferior del río Colorado. Parte de los resultados obtenidos son presentados en este trabajo, cuyos objetivos son: a) presentar y discutir las características tecno-tipológicas del conjunto lítico, con énfasis en el aprovisionamiento de materias primas líticas, el modo de gestión de las mismas, las intenciones y técnicas de talla, los métodos de débitage y façonnage, las chaînes opératoires y la diversidad artefactual registrada; b) discutir la asignación funcional del sitio y la extensión de las ocupaciones, para lo cual se presenta el estado e integridad de la muestra de artefactos líticos vinculada con los aspectos estratigráficos, cronológicos y de los principales procesos de formación implicados y c) analizar cómo se ajustan los resultados del sitio con el modelo tecnológico areal existente.

\section{Estratigrafía y cronología}

Como se mencionó anteriormente, los materiales fueron recuperados de superficie, de sondeos, de muestreos sub-superficiales y de excavaciones (Figura 2). A pesar de las diferentes procedencias de los materiales, todos ellos estuvieron originalmente en posición estratigráfica y su ubicación actual es el producto de procesos de deflación diferencial que afectaron los bordes de la duna (Martínez y Martínez 2011). De acuerdo con esto, se toman las cuadrículas uno y dos (Figura 2) como referencia estratigráfica para controlar la posición de los materiales, su relación con los fechados radiocarbónicos y para la delimitación del componente arqueológico.

A través de la secuencia estratigráfica de la duna, el Dr. C. F. Dubois identificó las unidades estratigráficas A, C1 y C2, 2A, 2AC y 2C (Figura 3). El análisis de la distribución vertical de los elementos óseos, líticos y cerámicos a lo largo de la columna mostró que la mayor frecuencia de los mismos se localiza en la parte inferior de las unidades 2A, 2AC y en la parte superior de la $2 \mathrm{C}$, sector de la estratigrafía que se corresponde con eventos pedogenéticos y donde fue definido un componente arqueológico (ver discusión en Armentano 2012 y Stoessel 2012). De este sector de la estratigrafía se obtuvieron cuatro fechados radiocarbónicos (AMS) sobre desechos de fractura helicoidal de guanaco que arrojaron edades de $1615 \pm 50$ (AA-53331; $\delta C^{13} \%$ $-17.8), 1935 \pm 44\left(\mathrm{AA}-53332 ; \delta C^{13} \%\right.$-16.2); $1749 \pm$ $64\left(\mathrm{AA}-88418 ; \delta C^{13}\right.$ - 19.7) y $1775 \pm 66$ (AA-88419; $\delta C^{13}$ - 18.8) (Martínez 2008-2009; Martínez y Martínez 2011). En suma, la distribución más frecuente de los materiales ocurre en el sector correspondiente al suelo enterrado, los resultados tafonómicos indican procesos que operaron esencialmente in situ y la coherencia de los fechados radiocarbónicos sustentan la definición del componente arqueológico y su cronología entre $c a$. 1900-1600 años AP.

\section{Base de recursos líticos}

En base a la bibliografía geológica, las observaciones en el terreno y la realización de muestreos de materias primas líticas, se observa que las poblaciones que

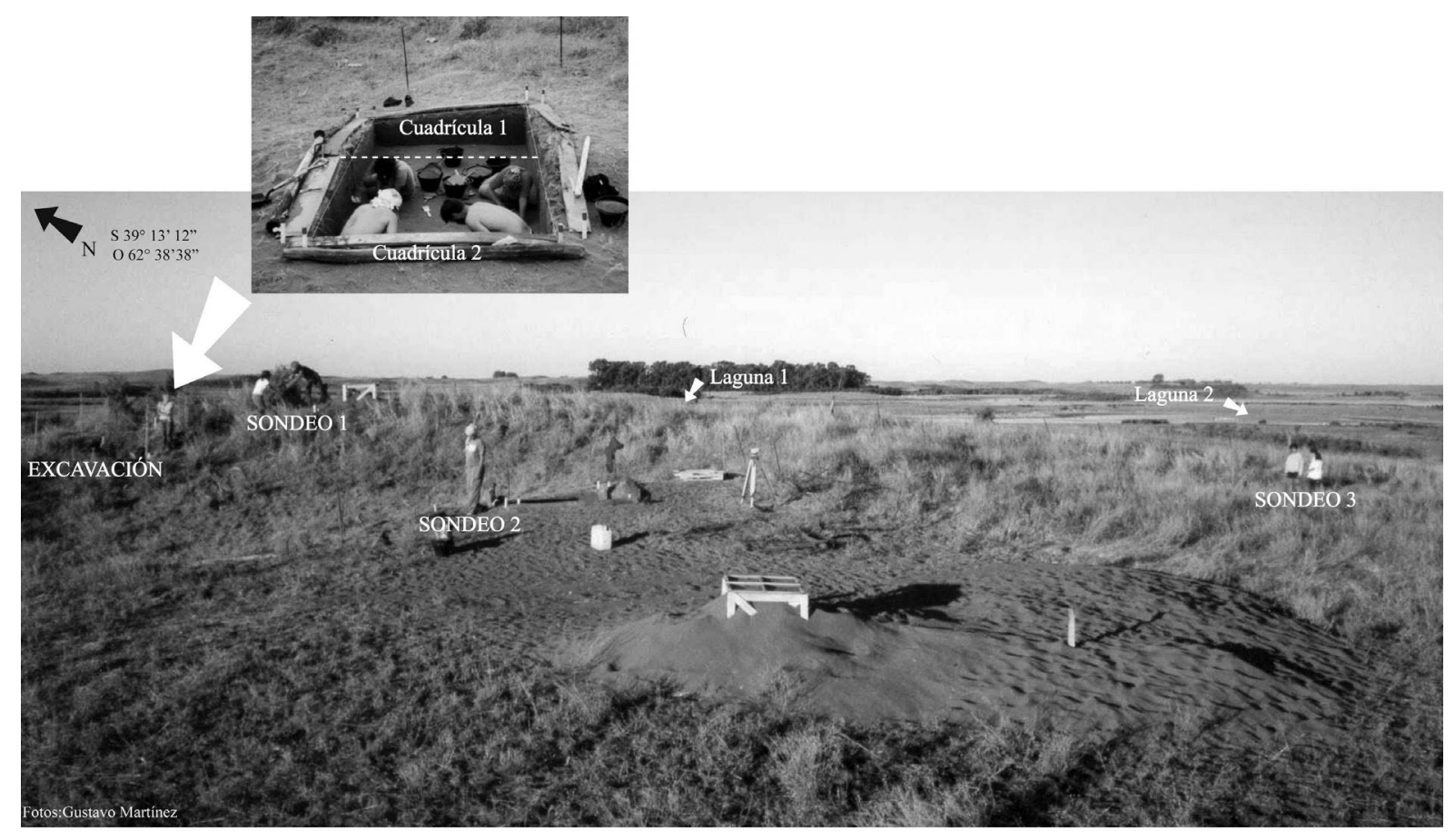

Figura 2.- El sitio Loma Ruiz 1. Médano y lagunas adyacentes. Localización de las cuadrículas y sondeos (modificado de Armentano 2012). Figures 2.-The Loma Ruiz 1 site. Dune and adjacent lagoons. Location of the excavation units and test pits (modified from Armentano 2012) 
ocuparon el área del curso inferior del río Colorado durante el Holoceno tardío contaron con una variada oferta de rocas de diferentes calidades para la talla y para la confección de artefactos de molienda (Armentano 2012). Los instrumentos tallados fueron confeccionados casi exclusivamente sobre rodados. Un factor crítico que seguramente influenció las estrategias de aprovisionamiento y selección de las materias primas aptas para la talla, además de la calidad para la fractura concoide, fue el tamaño, la morfología y la distribución espacial de los rodados seleccionados. Si bien estos son abundantes y se encuentran disponibles en toda el área de estudio, se registran zonas donde habría una mayor abundancia de ciertos tamaños y morfologías específicas (e.g.; rodados patagónicos - ca. 32-64 mm -, fluviales - ca. 64-128 mm -, depósitos gravosos marinos -ca. 20128 mm-, ver discusión en Armentano 2012; Fidalgo y Riggi 1970; Bonomo y Prates 2006). Son rodados locales aquellos disponibles en las inmediaciones de los sitios, tanto sueltos en superficie como en relictos de antiguas terrazas. Los rodados que se encuentran a una distancia mayor a 20 km de los sitios se los consideró areales, en tanto que los depósitos gravosos ubicados en la franja costera son locales o areales dependiendo de la distancia al sitio considerado. Esta diferenciación espacial de los rodados se ve acompañada por características morfológicas, litológicas y de tamaño ya reseñadas en la bibliografía geológica (ver detalles en Armentano 2012).

En el caso de las rocas empleadas para los artefactos de molienda, las únicas fuentes disponibles en el área son los afloramientos puntuales del manto de areniscas rionegrenses. El mismo, es un recurso bien localizado en ciertos sectores del paisaje, abundante, predecible y de friabilidad variable (ver referencias en Zavala y Freije 2001). La explotación de este tipo de arenisca ha sido registrada tanto en el área de estudio (Armentano 2004, 2007; Bayón et al. 2004) como en la Península de San Blas (Torres 1922), en el curso medio del río Negro (Prates
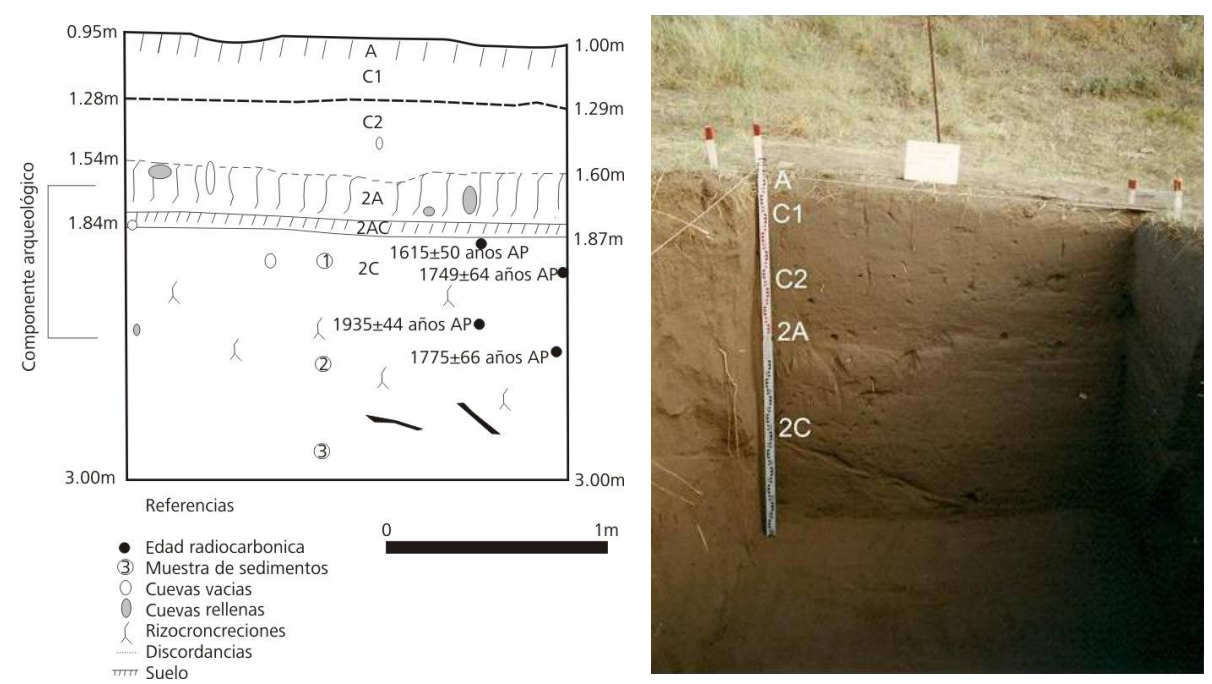

Figura 3. Secuencia estratigráfica, ubicación del componente arqueológico y cronología radiocarbónica (modificado de Stoessel 2012).

Figures 3. Stratigraphic sequence, location of the archaeological component and radiocarbon chronology (modified from Stoessel 2012).
2008) y en las cuencas de los ríos Curacó y Chadileuvú, estas últimas en la provincia de La Pampa (Berón 2004; Carrera Aizpitarte 2006).

El empleo de materias primas de origen extra-areal se refiere principalmente a la presencia de rocas cuarcíticas y un tipo de calcedonia traslúcida. La cuarcita es la roca más representada en el registro arqueológico pampeano. Las rocas de mayor explotación en la subregión Pampa Húmeda son las ortocuarcitas del Grupo Sierras Bayas (Bayón et al. 1999; Flegenheimer y Bayón 2002), las cuales están muy poco representadas en la provincia de La Pampa (Berón 2004; Carrera Aizpitarte 2006), en el curso inferior del río Colorado (Armentano 2004) y en el curso medio del río Negro (Prates 2008). Las metacuarcitas del sistema de Ventania se explotaron principalmente a escala areal (hasta $60 \mathrm{~km}$ de las fuentes) y son rocas secundarias a escala regional (Flegenheimer y Bayón 2002). En los sitios del curso inferior del río Colorado, las metacuarcitas son más frecuentes que las ortocuarcitas siendo, en general empleadas para la confección de artefactos de molienda (Armentano 2004, 2012; Bayón et al. 2004). La otra materia prima considerada como potencialmente extra-areal es una calcedonia traslúcida que presenta ciertas características que la distinguen de las calcedonias recuperadas en los rodados locales y areales. Estas calcedonias translúcidas provendrían de la meseta de Somuncurá (Pcia. de Negro) y sus fuentes se localizarían a ca. 600 km al SO del área de estudio (Miotti et al. 2004). A diferencia de las calcedonias que provienen de rodados locales y areales, las calcedonias translúcidas son materias primas muy homogéneas (Hermo 2008), en las cuales están ausentes las marcas de conos incipientes (presentes en las materias primas procedentes de rodados) y los módulos de tamaño de los artefactos confeccionados en las mismas son mayores a los esperados a partir de la utilización de rodados areales o locales. La presencia de rodados de este tipo de calcedonia traslúcida de tamaño grande (mayores a $71 \mathrm{~mm}$ ) fue registrada en la costa O del Golfo San Matías (Cardillo y Scartascini 2007), distante ca. $200 \mathrm{~km}$ del área de estudio. Finalmente, en uno de los sitios del área (El Caldén) se detectó mediante el análisis de fluorescencia de rayos $X$ (XRF) la presencia de obsidiana procedente del Cerro Huenul, en la provincia de Neuquén (Armentano 2012; Barberena et al. 2011). Sin embargo, todavía no se realizaron este tipo de análisis sobre los artefactos de posible obsidiana del sitio Loma Ruiz 1. Lo discutido anteriormente da cuenta de una base de recursos líticos para el Holoceno tardío 
donde el aprovisionamiento de materias primas involucró un rango de distancias variables, que van desde rocas accesibles localmente hasta otras que se encuentran a ca. 700 km de distancia (Armentano 2012) (ver Figura 1).

\section{La colección lítica del sitio Loma Ruiz 1: estado e integridad}

El conjunto lítico del sitio Loma Ruiz 1 asciende a 763 artefactos que fueron recuperados mediante diferentes metodologías de recolección:

I. En la recolección superficial sobre la hoyada de 4860 $\mathrm{m}^{2}$, se recuperaron 164 piezas líticas, lo que representa una densidad artefactual de 0,033 ítems $/ \mathrm{m}^{2}$.

II. En la excavación de dos cuadrículas (8 $\mathrm{m}^{2} \times 1,95 \mathrm{~m}$ profundidad) se recuperaron 396 piezas líticas en 15,6 $\mathrm{m}^{3}$, es decir 25,38 ítems $/ \mathrm{m}^{3}$.

III. En el sondeo 1 ( $1 \mathrm{~m}^{2} \times 1,90 \mathrm{~m}$ profundidad) se recolectaron 42 artefactos líticos en 1,90 $\mathrm{m}^{3}$; lo que equivale a 22,10 ítems $/ \mathrm{m}^{3}$.

IV. En el sondeo 2 ( $1 \mathrm{~m}^{2} \times 1,90 \mathrm{~m}$ profundidad) se recuperaron 59 piezas líticas en 1,9 $\mathrm{m}^{3}$, es decir 31,05 ítems $/ \mathrm{m}^{3}$.

V. Finalmente, en el sondeo $3\left(1 \mathrm{~m}^{2} \times 2 \mathrm{~m}\right.$ de profundidad) se hallaron 102 artefactos en $2 \mathrm{~m}^{3}$, lo que equivale a 51 ítems $/ \mathrm{m}^{3}$.

En este trabajo solo se considerarán los materiales correspondientes a la recolección superficial y la excavación, es decir el 73,39\% $(n=560)$ del total del sitio. Antes de proceder al análisis tecno-tipológico, se separaron del conjunto arqueológico los litos sin modificación. Estos últimos, son exclusivamente rodados de tamaño guija (4-16 mm) que formaban parte de la matriz arenosa del médano. Durante las tareas de campo, se detectaron rodados frecuentemente disponibles en superficie, no concentrados y cercanos al sitio. Estos son en su mayoría de tamaño pequeño (30-50 mm) y eventualmente se registran de tamaños medianos y grandes, aunque estos últimos son más difíciles de obtener (ver Armentano 2012). En consecuencia, la presencia de rodados de tamaños medianos y grandes aptos para la talla en el conjunto de la excavación y la hoyada de Loma Ruiz 1 es indicativa de una acción de traslado antrópico, dado que no hay evidencias que permitan explicar un transporte natural de los mismos. Del mismo modo, existen fragmentos sin evidencias de modificación antrópica de areniscas rionegrenses, cuya presencia en el sitio sería también consecuencia del traslado. El afloramiento identificado más cercano a Loma Ruiz 1 es un domo que se encuentra en el sitio Campo Calvo, a ca. $10 \mathrm{~km}$ en sentido NE. El mismo es considerado una cantera potencial ya que no se registró evidencia de explotación de estas areniscas in situ.

En cuanto al estado de conservación del material lítico (superficie y estratigrafía), el mismo presenta un estado general bueno, sin presencia de alteraciones mecánicas, pátinas (alteraciones físicas o químicas) ni adherencias. Todas las piezas, incluso las de superficie, carecen de lustre producto de la abrasión eólica (corrasión). Estas observaciones permiten establecer que se trataría de un conjunto con poco tiempo de exposición en superficie. Las únicas alteraciones detectadas son consecuencia del daño térmico y se registraron en muy baja frecuencia (dos artefactos sobre rocas silíceas) entre el material de la excavación. Del mismo modo, el grado de integridad del conjunto permitió establecer tres raccords ${ }^{3}$ y un remontaje. Uno de los raccords se realizó entre tres fragmentos de una lasca bipolar de tufita procedente del conjunto de superficie. La fractura de la lasca es longitudinal, separándola en dos mitades casi simétricas, además de un pequeño fragmento cerca del talón. Dicha fractura puede ser de origen tecnológico (e.g.; fractura en split). Otro raccord se estableció entre una lasca de façonnage de ortocuarcita de Tandilia fragmentada y la porción distal de la misma, ambas procedentes del nivel 1,44-1,54m de la cuadrícula dos (inmediatamente arriba del inicio del paleosuelo; ver Figura 3). En este caso, la fractura es oblicua en uno de los vértices distales de la lasca, lo cual puede ser consecuencia de un impacto postdepositacional. El tercer raccord se estableció entre dos fragmentos de una lasca de débitage en el conjunto de superficie. La fractura presenta características similares a la de la primera lasca descripta, por lo que se considera que posiblemente esta lasca se fracturó en el momento de la talla. Finalmente, el único remontaje del sitio se realizó entre dos lascas bipolares, una proveniente del nivel $2,40 \mathrm{~m}-2,45 \mathrm{~m}$ de la cuadrícula 1 y otra del nivel $1,24 \mathrm{~m}-1,34 \mathrm{~m}$ de la cuadrícula 2 . Dicho remontaje permitió verificar por un lado, una separación en profundidad de más de un metro $(1,20 \mathrm{~m})$ entre las piezas ensambladas ${ }^{4}$, ambas fuera de los límites de los niveles correspondientes al paleosuelo (Figura 3). Por otro lado, el agente que provocó dicho desplazamiento no produjo marcas identificables sobre el material lítico, por lo que es necesario completar esta observación con la información brindada por otras líneas de investigación. En este sentido, como ya fue destacado, los estudios tafonómicos indican que el conjunto arqueofaunístico fue principalmente afectado por la acción de raíces y el deterioro químico (Alcaráz 2012; Stoessel 2012). Las primeras se encuentran presentes a lo largo de todo el perfil estratigráfico y podrían ser la causa del desplazamiento vertical de los materiales líticos. Finalmente, una vez finalizadas las tareas de remontajes el conjunto de materiales de superficie se vio reducido a 161 artefactos y el conjunto de estratigrafía a 395 piezas, es decir, un total de $n=556$.

\section{Categorias artefactuales y materias primas}

\section{Recolección de Superficie}

El conjunto lítico recuperado en la recolección superficial $(\mathrm{N}=161)$ se compone principalmente de desechos de talla 
producto de acciones de débitage, los cuales representan el $65,84 \%(n=106)$, en tanto que los desechos producto de las operaciones de façonnage y confección de instrumentos corresponden al 13,66\% ( $n=22)$ del total. Los núcleos tienen una frecuencia del 8,07\% ( $n=13)$, los instrumentos no tallados (asociados a la molienda y a la talla) constituyen el $7,45 \%(n=12)$ y los instrumentos tallados el 3,11\% $(n=5)$. Finalmente las pièces esquillées ${ }^{5}$ representan el $1,24 \%(n=2)$ y un posible instrumento corresponde al $0,62 \%$ de la muestra total $(n=1)$ (Tabla 1$)$.

En cuanto a las materias primas, la categoría más frecuente es la de las calcedonias con el 22,36\% $(n=36)$. Si se discrimina al interior de esta clase, entre las calcedonias de origen local y/o areal y aquellas posiblemente extra-areales (ver Base de recursos líticos), las primeras representan el $16,77 \%(n=27)$, en tanto las segundas el $5,59 \%(n=9)$ del conjunto de superficie. Dicha frecuencia las ubica en el tercer lugar detrás de las rocas silíceas con el $18,63 \%(n=30)$ y la categoría de basaltos o andesitas con el 17,39\% $(n=28)$. Entre las rocas cuarcíticas extraareales, la metacuarcita de Ventania representa el 9,94\% $(n=16)$, en tanto que la ortocuarcita de Tandilia tiene una frecuencia del 8,7\% $(n=14)$. La arenisca rionegrense ha sido empleada exclusivamente en artefactos de molienda o yunques y representa el 6,21\% $(n=10)$ de la muestra de superficie. El conjunto de rocas indeterminadas posee el $4,97 \%(n=8)$, la tufita el $4,35 \%(n=7)$ y la dacita el $3,11 \%(n=5)$. Una arenisca indeterminada cuenta con el $2,48 \%(n=4)$, la riolita con el $1,24 \%(n=2)$ y una posible obsidiana representa el $0,62 \%(n=1)$ (Tabla 1).
Resumiendo, considerando la representación de las diferentes categorías artefactuales según cada uno de los tipos de rocas (Tabla 1), se destaca que las materias primas más frecuentes (rocas silíceas, basalto o andesita y calcedonias locales y/o areales) dan cuenta de la mayor variabilidad artefactual. Las rocas cuarcíticas tienen una proporción similar entre desechos de débitage avanzado y desechos de façonnage. El único núcleo sobre metacuarcita de Ventania recuperado se encuentra agotado. El conjunto de estas últimas observaciones puede ser considerado como un indicador de que parte de las actividades de inicio de la talla no se llevaron a cabo en el sitio, lo cual es esperable para materias primas extra-areales. En cuanto a las areniscas rionegrenses, estas están representadas por fragmentos, desechos e instrumentos terminados, asociados a la molienda o a la talla, por lo que se estima que parte de la confección y/o terminación de los mismos se realizó en el sitio. Finalmente, las materias primas menos representadas (frecuencia menor al 5\%) se registran en una muy baja variabilidad artefactual asociada a momentos de prueba de materia prima.

\section{Materiales de la excavación}

El conjunto artefactual recuperado de la excavación de dos cuadrículas $(n=395)$ se compone principalmente de desechos de talla, producto tanto de actividades de façonnage y confección de instrumentos $(47,59 \%$; $\mathrm{n}=188)$, como de débitage $(46,84 \% ; \mathrm{n}=185)$. Los bâtonnets ${ }^{5}$ representan el $2,03 \%(n=8)$ de la muestra. Por

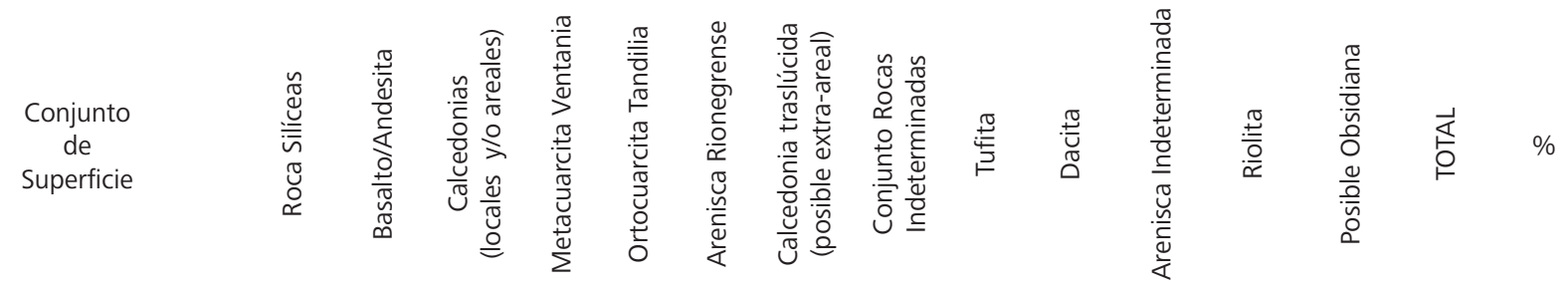

\begin{tabular}{|c|c|c|c|c|c|c|c|c|c|c|c|c|c|c|c|}
\hline $\begin{array}{l}\text { Desechos de talla } \\
\text { (debitage) }\end{array}$ & 20 & 22 & 25 & 9 & 9 & 1 & 4 & 7 & 4 & 2 & 1 & 2 & - & 106 & 65,84 \\
\hline $\begin{array}{l}\text { Desechos de talla } \\
\text { (façonnage y confección) }\end{array}$ & 3 & 3 & - & 6 & 4 & - & 4 & 1 & - & 1 & - & - & - & 22 & 13,66 \\
\hline Núcleos & 4 & 2 & 2 & 1 & - & - & - & - & 3 & - & - & - & 1 & 13 & 8,07 \\
\hline Instrumentos no tallados & - & - & - & - & - & 9 & - & - & - & - & 3 & - & - & 12 & 7,45 \\
\hline Instrumentos tallados & 2 & 1 & - & - & 1 & - & - & - & - & 1 & - & - & - & 5 & 3,11 \\
\hline Pièces Esquillées & 1 & - & & - & - & - & 1 & - & - & - & - & - & - & 2 & 1,24 \\
\hline Posible Instrumento & - & - & - & - & - & - & - & - & - & 1 & - & - & - & 1 & 0,62 \\
\hline TOTAL & 30 & 28 & 27 & 16 & 14 & 10 & 9 & 8 & 7 & 5 & 4 & 2 & 1 & 161 & 100 \\
\hline$\%$ & 18,6 & 17,4 & 16,8 & 9,9 & 8,7 & 6,2 & 5,6 & 4,9 & 4,4 & 3,1 & 2,6 & 1,2 & 0,6 & 100 & \\
\hline
\end{tabular}


su parte, los instrumentos tallados tienen una frecuencia del $1,52 \%(n=6)$. Los núcleos están representados con el $1,01 \%(n=4)$. Las pièces esquillées y los posibles instrumentos poseen el $0,51 \%(n=2)$ cada uno. No se registraron en este conjunto instrumentos no tallados asociados a la molienda y fragmentos de arenisca rionegrense (Tabla 2).

En lo que se refiere a las materias primas, las más frecuentes son las calcedonias (locales y/o areales) con el 25,82\% ( $n=102)$, seguidas por las rocas silíceas con el $20,25 \%(n=80)$ y la categoría de basaltos o andesitas con el $16,46 \%(n=65)$. Las proporciones de las rocas cuarcíticas están invertidas en relación con la colección de superficie. En estratigrafía, es más frecuente la ortocuarcita de Tandilia con el 12,66\% ( $n=50)$, en tanto que en la colección de superficie ésta sólo alcanza el 8,7\% (ver más arriba). La metacuarcita de Ventania constituye el 2,03\% $(n=8)$ del conjunto de la excavación, contra el $9,94 \%$ en el conjunto de superficie. Las restantes materias primas de la excavación son la dacita con el 7,59\% ( $\mathrm{n=30}$, la calcedonia traslúcida (posiblemente extra-areal) está presente únicamente en lascas de retoque con el 4,81\% $(n=19)$ y el conjunto de rocas indeterminadas posee el $4,30 \%(n=17)$. La arenisca indeterminada y la tufita presentan una frecuencia de $2,03 \%(n=8)$ cada una. Finalmente, la riolita y una posible obsidiana tienen las frecuencias más bajas con $1,52 \%(n=6)$ y $0,51 \%(n=2)$, respectivamente (Tabla 2 ).

Cruzando la información de la representación de las diferentes categorías artefactuales con cada tipo de roca explotada, se observa que hay una alta representación de desechos de talla producto del débitage (avanzado), façonnage y confección de instrumentos en calcedonias (todas las procedencias), rocas silíceas, basalto o andesita, ortocuarcita de Tandilia y dacita. No obstante, no se recuperaron los núcleos de estas materias primas en la excavación, lo cual indica que las etapas de inicio no se habrían llevado a cabo en el sitio. Los núcleos en estratigrafía son escasos ( $n=4 ; 1,01 \%)$ y están realizados sobre rodados de tamaño pequeño $(30-50 \mathrm{~mm}$ ) o se encuentran fragmentados (núcleos sobre riolita y rocas indeterminadas). Finalmente, las restantes materias primas están representadas exclusivamente por núcleos y desechos, por lo que puede considerarse que las actividades de inicio y débitage de estas rocas sí fueron llevadas a cabo en el sitio (Tabla 2).

\section{Comparación entre conjuntos}

En ambos conjuntos (superficie y estratigrafía), las rocas silíceas, el basalto o andesita y las calcedonias (locales y/o areales), se encuentran representadas en la mayoría de las categorías artefactuales correspondientes a las diferentes etapas de las chaînes opératoires de producción lítica (núcleos, desechos de débitage, façonnage y confección e instrumentos; ver Tablas 1 y 2). En los dos conjuntos los desechos son la categoría artefactual más representada, sin embargo, los que son producto de actividades de confección y façonnage se encuentran mejor representados en estratigrafía. Los

\begin{tabular}{|c|c|c|c|c|c|c|c|c|c|c|c|c|c|c|}
\hline $\begin{array}{l}\text { Conjunto } \\
\text { de Estratigrafía }\end{array}$ & 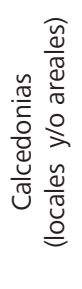 & 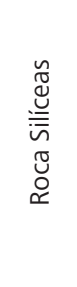 & $\begin{array}{l}\frac{0}{\sqrt[T]{5}} \\
\frac{0}{0} \\
\frac{C}{\Delta} \\
0 \\
\frac{ \pm}{\sqrt{0}} \\
\stackrel{0}{0} \\
\infty\end{array}$ & 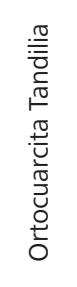 & 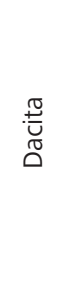 & 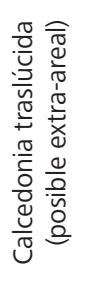 & 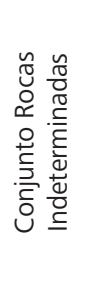 & 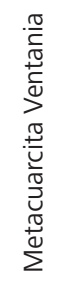 & 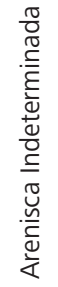 & $\underbrace{\frac{\pi}{2}}_{i}$ & $\frac{\stackrel{0}{ \pm}}{\frac{D}{\infty}}$ & $\begin{array}{l}\frac{0}{2} \\
\frac{\pi}{0} \\
\frac{0}{0} \\
\frac{0}{0} \\
0 \\
\frac{0}{0} \\
\frac{0}{n} \\
0 \\
0\end{array}$ & $\underset{\vdash}{\stackrel{1}{\leftarrow}}$ & $\%$ \\
\hline $\begin{array}{l}\text { Desechos de talla (façonnage } \\
\text { y confección ) }\end{array}$ & 59 & 50 & 23 & 21 & 12 & 19 & - & 4 & - & - & - & - & 188 & 47,59 \\
\hline Desechos de talla (débitage) & 33 & 25 & 41 & 29 & 18 & - & 14 & 4 & 8 & 8 & 3 & 2 & 185 & 46,84 \\
\hline Bâtonnets & 8 & - & - & - & - & - & - & - & - & - & - & - & 8 & 2,03 \\
\hline Instrumentos tallados & 2 & 3 & - & - & - & - & 1 & - & - & - & - & - & 6 & 1,52 \\
\hline Núcleos & - & - & - & - & - & - & 2 & - & - & - & 2 & - & 4 & 1,01 \\
\hline Pièces Esquillées & - & 1 & - & - & - & - & - & - & - & - & 1 & - & 2 & 0,51 \\
\hline Posible Instrumento & - & 1 & 1 & - & - & - & - & - & - & - & 0 & - & 2 & 0,51 \\
\hline Instrumentos no tallados & - & - & - & - & - & - & - & - & - & - & 0 & - & 0 & 0 \\
\hline TOTAL & 102 & 80 & 65 & 50 & 30 & 19 & 17 & 8 & 8 & 8 & 6 & 2 & 395 & 100 \\
\hline$\%$ & 25,8 & 20,3 & 16,5 & 12,7 & 7,6 & 4,8 & 4,3 & 2,0 & 2,0 & 2,0 & 1,5 & 0,5 & 100 & \\
\hline
\end{tabular}

Tabla 2. Categorías artefactuales y materias primas del conjunto de excavación.

Table 2. Artifact categories and lithic raw materials recovered from excavation units 1 and 2. 
núcleos de las rocas más representadas (e.g.; rocas silíceas, basalto o andesita y calcedonias locales y/o areales) sólo se encuentran en superficie. En lo que se refiere a las materias primas extra-areales, la diferencia más marcada se presenta entre las rocas cuarcíticas. En tal sentido, es necesario remarcar que la misma se debe a un aumento de la frecuencia de desechos de talla (façonnage y confección) de esta roca en el conjunto de estratigrafía. Las restantes materias primas extra-areales no presentan diferencias significativas, aunque es claro el patrón de una mayor proporción de desechos pequeños en la excavación. Los fragmentos de pièces esquillées (bâtonnets), solamente se recuperaron en estratigrafía. Los instrumentos no tallados y las areniscas rionegrenses sólo se encuentran en superficie.

En síntesis, las diferencias señaladas hacen referencia a una mejor representación en estratigrafía de categorías artefactuales de tamaño pequeño (lascas de retoque y bâtonnets) y a la ausencia en excavación de artefactos que son de tamaños medianos o grandes (núcleos y artefactos de molienda). Ambos conjuntos presentan similares tendencias en la explotación de materias primas y presencia de categorías artefactuales generales, aunque con distintas frecuencias. La distribución diferencial de tamaños y ciertas materias primas sería el producto de procesos de formación de sitio, como la erosión diferencial de los bordes de la duna que expuso materiales que originalmente estaban en estratigrafía
(Martínez et al. 2011; Martínez y Martínez 2011). En consecuencia, este patrón no sería el producto de elecciones o condicionantes tecnológicos, de selección de materias primas o de cambios en los objetivos de la talla. Por lo tanto, se asume que ambos conjuntos son tecnológicamente comparables. En otras palabras, si bien en la actualidad se registran dos expresiones de este registro arqueológico (uno superficial y otro en estratigrafía), los materiales habrían estado originalmente asociados en estratigrafía como parte de un mismo componente arqueológico (ver más arriba). Las tendencias similares que muestra el análisis tecnológico sustentan esta situación, ya que ambas colecciones se presentan como una muestra coherente internamente que, a su vez, posibilita el análisis y reconstrucción de las chaînes opératoires a partir de la información procedente de ambos conjuntos. Los totales de ambos contextos discriminados según tipos de lascas y materias primas son retomados posteriormente.

\section{Las intenciones de talla: los instrumentos tallados}

\section{Materias primas y soportes}

El número total de instrumentos (superficie y estratigrafía) asciende a 11 piezas (Tabla 3 y Figura 4). Al interior de esta categoría artefactual, se encuentran representadas solo algunas de las materias primas recuperadas en el sitio. En este sentido, las rocas silíceas corresponden

\begin{tabular}{|c|c|c|c|c|c|c|c|c|c|}
\hline & Instrumentos tallados & 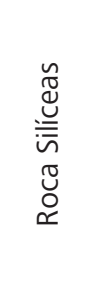 & 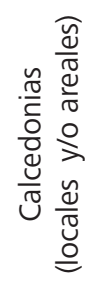 & 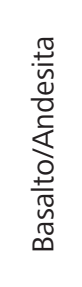 & 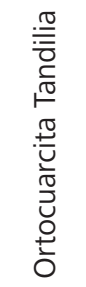 & 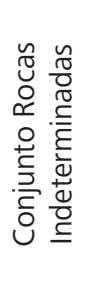 & 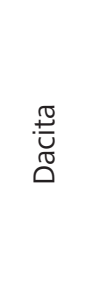 & $\stackrel{\frac{1}{\leftarrow}}{\stackrel{\ominus}{\ominus}}$ & $\%$ \\
\hline \multirow{4}{*}{ 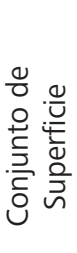 } & Filo Bisel Asimétrico & - & - & - & - & - & 1 & \multirow{5}{*}{5} & \multirow{5}{*}{45,45} \\
\hline & Raspador Frontal & 1 & - & - & - & - & - & & \\
\hline & $\begin{array}{l}\text { Instrumento Compuesto } \\
\text { (Raspador + Cuchillos+ Punta Destacada) }\end{array}$ & - & - & 1 & - & - & - & & \\
\hline & $\begin{array}{l}\text { Instrumento Compuesto } \\
\text { (Raspador + Borde Filo Bisel Asimétrico) }\end{array}$ & 1 & - & - & - & - & - & & \\
\hline \multirow{9}{*}{ 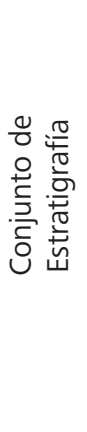 } & Raclette & - & - & - & 1 & - & - & & \\
\hline & Raspador Frontal & - & 1 & - & - & - & - & \multirow{6}{*}{6} & \multirow{6}{*}{54,54} \\
\hline & Raspador Lateral & 1 & - & - & - & - & - & & \\
\hline & Raspador fragmentado Indeterminado & - & - & - & - & 1 & - & & \\
\hline & Cuchillo Lateral & 1 & - & - & - & - & - & & \\
\hline & Instrumento Indeterminado (Raspador?) & 1 & - & - & - & - & - & & \\
\hline & Fragmento de Instrumento & - & 1 & - & - & - & - & & \\
\hline & TOTAL & 5 & 2 & 1 & 1 & 1 & 1 & 11 & 100 \\
\hline & $\%$ & 45,45 & 18,18 & 9,09 & 9,09 & 9,09 & 9,09 & 100 & \\
\hline
\end{tabular}

Tabla 3. Instrumentos tallados y materias primas de superficie y estratigrafía.

Table 3. Stone tools and raw materials recovered from surface and stratigraphic assemblages. 


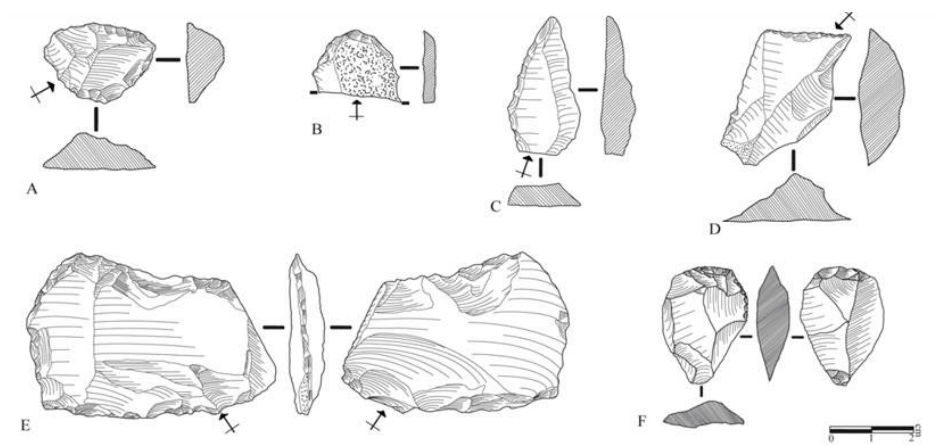

Figura 4.- Instrumentos tallados y lascas con rastros complementarios

Figure 4. - Knapping tools and utilized flakes

Conjunto de la recolección de superficie: A. FCS. LR1.RS.75. Instrumento compuesto (Raspador + Borde Filo Bisel Asimétrico) sobre roca silícea. B. FCS.LR1.RS.79 Raspador frontal sobre roca silícea. C. FCS.LR1.RS.206. Raclette sobre ortocuarcita Tandilia. D. FCS.LR1.RS.69. Filo Bisel Asimétrico sobre dacita. E. FCS.LR1.RS.10. Instrumento compuesto (Raspador + Cuchillos + Punta destacada) sobre basalto o andesita. F. FCS.LR1.RS.12. Lasca bipolar con rastros complementarios sobre dacita.

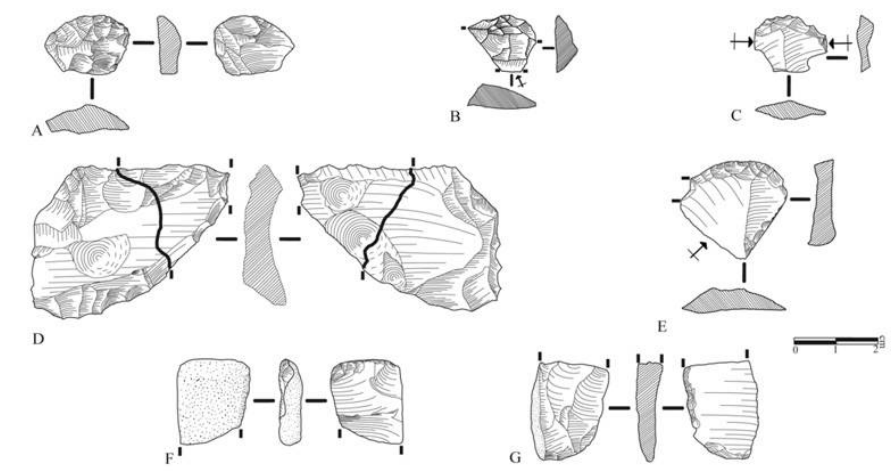

Figura 4.- Instrumentos tallados y lascas con rastros complementarios

Figure 4. - Knapping tools and utilized flakes

Conjunto de la excavación: A. FCS. LR1.686. Raspador frontal sobre lasca de calcedonia (Cuadrícula 1). B. FCS.LR1.916. Raspador fragmentado sobre lasca de materia prima indeterminada. Posible vulcanita (Cuadrícula 2). C. FCS.LR1.907. Instrumento indeterminado Raspador? Sobre lasca bipolar de roca silícea. D. FCS.LR1.906. Cuchillo lateral sobre lasca centrípeta de roca silícea (Cuadrícula 2). E. FCS.LR1.905. Raspador lateral sobre lasca centrípeta de roca silícea (Cuadrícula 2). F. FCS.LR1.707. Lasca bipolar con rastros complementarios sobre roca silícea (Cuadrícula 1). G. FCS. LR1. 1010. Lasca bipolar con rastros complementarios sobre basalto o andesita (Cuadrícula 2)

al $45,45 \%(n=5)$ de los instrumentos, seguidas por las calcedonias (locales o areales) con el 18,18\% $(n=2)$. La categoría de basalto o andesita, la ortocuarcita de Tandilia (Grupo Sierras Bayas), la dacita y una roca indeterminada representan cada una el 9,09\% $(n=1)$ de la muestra (Tabla 3). Es decir, se encuentran representadas principalmente las rocas locales y/o areales de mejor calidad para la talla. Entre ellas, se han preferido las rocas silíceas y calcedonias. A esto se suma la presencia de una roca extra-areal, la ortocuarcita de Tandilia. Los instrumentos tallados presentan una escasa variabilidad tipológica. Dicha variabilidad fue contrastada con el material procedente de los sondeos y del muestro subsuperficial, reconociéndose las mismas clases tipológicas.
La producción del sitio Loma Ruiz 1 se concentró en la confección de raspadores y filos unifaciales. Posiblemente, también se hayan confeccionado piezas bifaciales (hay un fragmento de una posible punta de proyectil en uno de los sondeos), evidenciado por lascas de façonnage (ver más adelante; Tabla 4).

Los diferentes tipos de instrumentos han sido realizados sobre un limitado repertorio de soportes. El 54,54\% $(n=6)$ fue elaborado sobre soportes indeterminados, en el $36,36 \%(n=4)$ se emplearon lascas procedentes de débitage centrípeto o discoidal y solo un instrumento indeterminado (¿raspador?) (9,09\%) fue confeccionado sobre lasca bipolar. En lo que se refiere al estado, dentro 
de la categoría de instrumentos tallados, el 63,63\% $(n=7)$ están enteros, el $27,27 \%(n=3)$ se encuentran fragmentados y el porcentaje restante corresponde a un fragmento. Entre los instrumentos fragmentados, se determinó que en el 18,18\% $(n=2)$ de los casos la fractura se produjo en algún momento posterior al retoque (Figura 4).

\section{Instrumentos tallados}

Entre los instrumentos terminados se destacan numéricamente el grupo de los raspadores y posibles raspadores $(n=5)$. La mayoría de ellos han sido confeccionados sobre rocas silíceas $(n=3)$. En tres de los casos, el modo de extracción fue mediante la percusión directa dura; se ha registrado un caso de empleo de la percusión dura sobre yunque y un caso de modo indeterminado. En su mayoría, los soportes utilizados $(n=4)$ no conservan corteza. En cuanto a los tipos de lascas empleadas, tres son centrípetas o discoidales, una indeterminada y una bipolar. En lo que se refiere a las dimensiones, todos los raspadores se encuentran comprendidos entre los 13-23 mm de largo y 12-25 $\mathrm{mm}$ de ancho, lo cual puede estar asociado a que en la mayoría de los casos se han empleado lascas internas, de momentos avanzados del débitage. En lo que respecta al espesor, dos raspadores son poco espesos (entre 3-5 $\mathrm{mm}$ ) y tres son espesos (entre 5-7 mm). En lo que se refiere a la sección transversal, cuatro presentan sección plano-convexa y uno tiene una sección rectangular (Figura 4.1.B y Figuras 4.2.A, B, C y E).

La confección de los raspadores ha sido en todos los casos por medio del retoque unifacial de extensión corta y posición directa. La delineación del filo siempre es convexa. La morfología del retoque observado es escamosa regular $(n=2)$, escamosa escalonada $(n=2)$ y paralela corta $(n=1)$. La morfología escamosa escalonada es el resultado de la combinación de retoques y charnelas, posiblemente producidas durante el uso. Las evidencias del reactivado de los filos $(n=4)$ se pueden observar apreciando el perfil de los soportes utilizados (Figura 4.1.B y Figuras 4.2.A, B, C y E). En referencia al tamaño final de los raspadores descartados, la dimensión 15-13 $\mathrm{mm}$ de largo puede considerarse como el límite mínimo posible de reducción en la reactivación.

Se recuperaron, además, instrumentos compuestos (Figuras 4.1.A y E). Dos frentes de raspador fueron identificados dentro de este grupo. Uno de ellos, confeccionado sobre roca silícea (Figura 4.1.A), combina el frente de raspador con un filo en bisel asimétrico de inclinación aguda, cuyos lascados son irregulares, lo que podría ser consecuencia del enmangue. Este instrumento posee características morfológicas similares a las del resto del conjunto de los raspadores. El segundo caso (Figura 4.1.E), es completamente diferente. Este instrumento compuesto (raspador+ cuchillo+ punta destacada) fue realizado sobre una lasca grande $(47 \mathrm{~mm}$ de largo, $35 \mathrm{~mm}$ de ancho y $7 \mathrm{~mm}$ de espesor) de basalto o andesita. La misma fue obtenida por medio del débitage centrípeto, posiblemente por percusión directa dura. Las observaciones realizadas permitieron reconocer que los filos agudos son irregulares, uno de ellos con marcada delineación cóncava, los lascados de retoque son de tendencia alargada, planos y se superponen entre sí. Ambos filos son paralelos entre sí y de similar extensión (Figura 4.1.E). Todo esto permite suponer que se trata de bordes "retocados bipolarmente" o "machacados", consecuencia de una posible utilización del instrumento como cuña. Este último instrumento compuesto, se separa abiertamente del patrón estandarizado de los raspadores y se realizó sobre una roca areal de tamaño mediano-grande.

El grupo tipológico de las raclettes está representado por un solo instrumento que se encuentra entero, realizado sobre una lasca fragmentada de ortocuarcita de Tandilia sin reserva de corteza (Figura 4.1 C y Figura 8). La lasca utilizada como soporte es producto del façonnage realizado mediante la percusión directa blanda. Las dimensiones son $30 \mathrm{~mm}$ de largo, $16 \mathrm{~mm}$ de ancho y $7 \mathrm{~mm}$ de espesor. La sección es sub-rectangular. En lo que se refiere a las características del retoque, éste posee una delineación ligeramente convexa, los lascados son unifaciales ultramarginales en posición directa. La morfología de los lascados es escamosa regular. El filo se ubica en el lateral izquierdo y es largo. La inclinación del mismo es abrupta $\left(80^{\circ}\right)$, los lascados se distribuyen de manera continua a lo largo de todo el filo. La regularidad de los retoques sugiere el empleo de la técnica de presión. No se registraron raclettes sobre otros tipos de soportes o materias primas (locales o areales).

Se recuperó un solo ejemplar de filo en bisel asimétrico entero. El mismo fue realizado sobre una lasca fragmentada, posiblemente de dacita, la cual conserva un pequeño remanente de corteza (Figura 4.1.D). El soporte utilizado es producto de un débitage probablemente discoidal, obtenido por medio de la percusión directa dura. Las dimensiones son: $38 \mathrm{~mm}$ de largo, por $23 \mathrm{~mm}$ de ancho y $12 \mathrm{~mm}$ de espesor (muy espeso). La sección es triangular. El retoque se ubica en la parte proximal de la lasca, es de forma unifacial ultramarginal, en posición directa, la cual no se corresponde con el eje mayor de la lasca soporte. La morfología de los lascados es escamosa regular y continua. La delineación del filo es recta y la inclinación aguda (menor a $45^{\circ}$ ). La técnica de terminación es difícil de establecer macroscópicamente, no se descarta una posible modificación por utilización.

El único cuchillo fue recolectado en la excavación (Figura 4.2.D). El mismo fue confeccionado sobre una lasca de roca silícea grande (43 $\mathrm{mm}$ de longitud, $28 \mathrm{~mm}$ de ancho y $10 \mathrm{~mm}$ de espesor) sin remanente de corteza, de sección sub-rectangular. El soporte fue extraído por medio de la 
percusión directa dura, mediante un débitage centrípeto. El borde retocado posee una delineación rectilínea, los lascados son unifaciales en posición directa. La morfología de los lascados es escamosa regular. El filo se ubica en el lateral de la lasca. La inclinación del mismo es aguda $\left(30^{\circ}\right)$, los lascados se distribuyen de manera continua a lo largo de todo el filo. Este instrumento posee hoyuelos producto del daño térmico en ambas caras. La fractura del cuchillo ocurrió durante la manipulación en el análisis, posiblemente debilitado por la citada alteración. Un solo fragmento de instrumento sobre calcedonia fue recuperado de la excavación. El mismo está retocado unifacialmente y por su estado no puede considerarse dentro de ninguna de las clases antes citadas.

En resumen, la información procedente de los instrumentos tallados permite establecer que el índice de fragmentación del conjunto es bajo (36\%; $n=4)$. El aporte de cada una de las materias primas reconocidas es desigual, con predominio de las rocas silíceas. Existen dos grupos de tamaños de instrumentos: por un lado, los raspadores estandarizados que no superan en ningún caso los 30 $\mathrm{mm}$ (de largo o ancho) y, por otro lado, los instrumentos de mayores dimensiones (entre los 30-47 mm de largo) cuyos soportes son exclusivamente lascas producto de un débitage centrípeto. Probablemente, los últimos provengan de núcleos discoidales medianos-grandes (mayores a $50 \mathrm{~mm}$ ), escasamente representados en el sitio, en rocas areales y extra-areales. Existe también una producción ligeramente diferenciada de soportes tallados. Es decir, todos los instrumentos se confeccionaron sobre lascas, sin embargo, algunos raspadores se realizaron sobre lascas bipolares. Finalmente, la diferenciación entre los instrumentos ocurre durante la producción del filo por medio del retoque, en todos los casos unifacial. La distinción se manifiesta en la presencia o ausencia de regularidad de los filos, la inclinación y la extensión de los lascados.

La categoría artefactual de posibles instrumentos está compuesta por tres piezas. Las mismas están realizadas sobre lascas bipolares (Figura 4.1.F y Figuras 4.2. F y $\mathrm{G})$. Las materias primas empleadas han sido basalto $\mathrm{O}$ andesita, rocas silíceas y dacita, con una pieza cada una. Todos los posibles instrumentos son lascas con rastros complementarios continuos sobre un sector de un borde (mayoritariamente lateral), con una delineación rectilínea aguda o aguda convexa. Las dimensiones oscilan entre los 20-22 mm de largo y los 10-17 mm de ancho. En cuanto al espesor, están representados los rangos espeso y muy espeso. La similitud entre la delineación de los bordes naturales con rastros complementarios y los bordes con filos retocados en bisel asimétrico, sugieren un posible empleo de los bordes naturales de lascas bipolares en actividades similares a las de los citados instrumentos. Esta última observación deberá ser contrastada con análisis funcionales de base microscópica.
Las pièces esquillées (Figura 5) enteras son poco frecuentes dentro de toda la colección $(n=4)$, en tanto que los bâtonnets $(n=8)$ solo están representados en el conjunto lítico de estratigrafía. Con respecto a las materias primas, las pièces esquillées corresponden dos a rocas silíceas (Figura 5.C), una a calcedonia traslúcida (Figura 5.A) y una a riolita (Figura 5.B). Entre los bâtonnets solo se encuentran representadas las calcedonias (locales y/o areales). Dentro de esta categoría, las piezas enteras son todas pièces esquillées que pueden ser ubicadas en su mayoría en el estadio $2^{\circ}$ (sensu Tixier 1963). Las pièces esquillées sobre rocas silíceas y calcedonia traslúcida presentan evidencias de haber sido rotadas, es decir, tres o cuatro de sus polos tienen un machacado que avanza sobre las caras por lo cual, desde un punto de vista estrictamente tecnológico, es difícil establecer la diferencia entre masas centrales de núcleos bipolares o instrumentos (Figuras 5.A y C). Una única pièce esquillée, sobre riolita, posee uno de sus bordes parcialmente astillados y conserva aún corteza en el $80 \%$ de su cara dorsal (Figura 5.B). Los rasgos tecnológicos de la cara ventral permiten distinguir que no se trata de un producto de la talla bipolar sino de la percusión directa dura (posiblemente débitage facial). En consecuencia, esta pieza podría ser considerada como un instrumento modificado por uso (e.g.; ¿cuña?). Finalmente, en lo que respecta a las dimensiones, todas las piezas son bastante regulares, se encuentran entre los 28-16 mm de largo y entre los 29-14 mm de ancho. En cuanto al espesor, son todas muy espesas, oscilan entre los 9-8 $\mathrm{mm}$.

Los instrumentos no tallados $(n=12)$ sólo se encuentran en superficie representando el 7,45\% de ese conjunto. La materia prima más representada es la arenisca rionegrense, con el 75\% $(n=9)$. El 25\% $(n=3)$ está representado por materias primas indeterminadas. Los instrumentos no tallados asociados a actividades de talla (yunques y percutores) están confeccionados sobre estas rocas indeterminadas en su mayoría procedentes de rodados de tamaño mediano o grande. Dentro de este conjunto, los ecofactos corresponden a nódulos enteros de arenisca sin modificaciones antrópicas. Los artefactos indeterminados son piezas en las que no fue posible identificar grupos tipológicos específicos. En cuatro casos la posición de uso fue activa. En base al tamaño de grano de la materia prima y su carácter friable, las posibles funciones son la de abradidor o empleados para moler. La mayoría de las piezas no tienen evidencias de manufactura, lo cual puede relacionarse con un aprovechamiento de formas-base naturales cuyas morfologías no requirieren modificaciones para su uso (Matarrese 2009).

\section{Núcleos: materias primas y métodos de débitage}

La muestra de núcleos (Figura 6) representa el 3,05\% $(n=17)$ de todo el conjunto lítico analizado $(n=556)$. La 

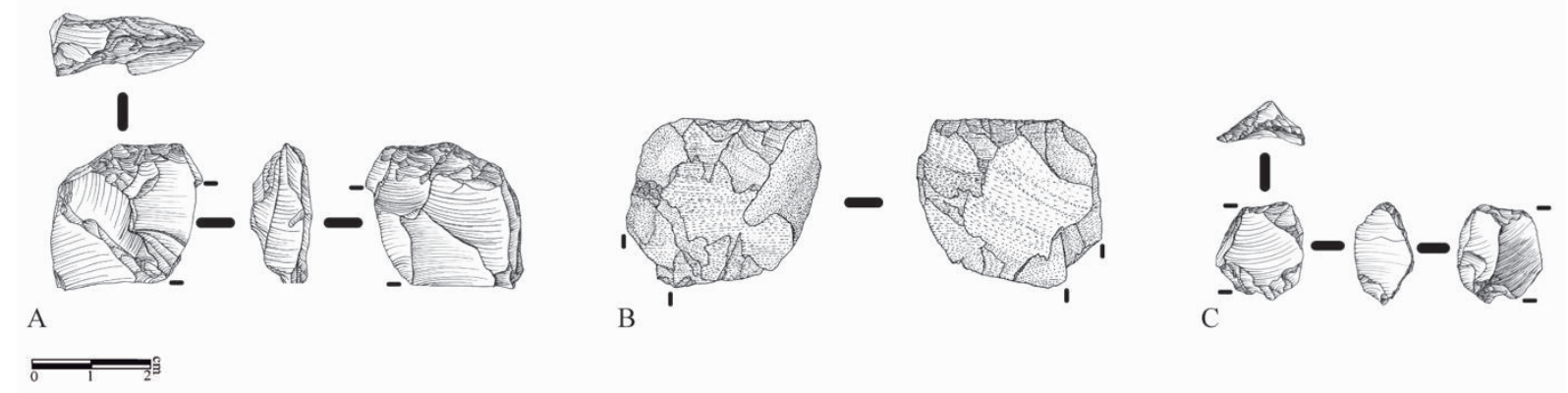

Figura 5.-Pièces esquillées. A. FCS. LR1.RS.65. Pièce esquillée sobre calcedonia traslúcida (Superficie). B. FCS. LR1.931 Pièce esquillée sobre lasca facial de riolita (Cuadrícula 2). C. FCS. LR1. 856. Pièce esquillée sobre roca silicea (Cuadrícula 2).

Figure 5.-Pièces esquillées

mayoría de ellos $(n=13)$ fueron recuperados en superficie (Tabla 1 y 2). Al interior de esta categoría artefactual, en el 23,52\% ( $n=4)$ de los casos se explotaron rocas silíceas (Figuras 6.1. A, D y F) seguidas por la tufita (Figura 6.1.C) con el $17,64 \%(n=3)$. Las calcedonias locales y/o areales (Figura 6.1.G), el basalto o andesita (Figura 6.1.B), la riolita (Figura 6.2.A) y el conjunto de rocas indeterminadas representan el $11,76 \%(n=2)$ cada una. Finalmente, la metarcuarcita de Ventania (Figura 6.1.E) y una posible obsidiana poseen el 5,88 \% $(n=1)$ cada una. No hay núcleos de calcedonia traslúcida.

En lo que se refiere al tipo de soporte utilizado, en el $82,35 \%(n=14)$ de los casos se han explotado rodados; los fragmentos indeterminados, nódulos y lascas espesas se emplearon en un $5,88 \%(n=1)$ cada uno. Entre los núcleos sobre rodados $(n=14)$, en el $50 \%(n=7)$ se utilizaron rodados de tamaño pequeño, en el 35,71\% $(n=5)$ los de tamaño mediano y en el $14,28 \%(n=2)$ los de tamaño grande. Cruzando la información procedente de las materias primas y los tamaños, entre los núcleos de tamaño pequeño están representadas todas las rocas explotadas. Entre los núcleos de tamaño mediano, solo se encuentran las rocas silíceas, la tufita, la riolita y el basalto o andesita. Finalmente, entre los núcleos de tamaño grande, solo se encuentran una roca silícea y la riolita. Con respecto al grado de avance en el débitage, el $64,70 \%$ ( $n=11$ ) de los núcleos y fragmentos corresponden a prueba de materia prima. El $17,64 \%(n=3)$ se encuentran en un grado avanzado del débitage y el $17,64 \%(n=3)$ restante están agotados. En cuanto a la forma de aplicación de la fuerza, en el 58,82\% $(n=10)$ se llevó a cabo mediante la percusión sobre yunque (en split), en el $35,29 \%(n=6)$ por medio de la percusión directa y en el $5,88 \%(n=1)$ restante a través de la percusión sobre apoyo. Con respecto al modo, en el $17,64 \%(n=3)$ de los casos no se pudo determinar con exactitud, en tanto que para el $82,35 \%(n=14)$ restante se empleó la percusión directa dura, en sus diferentes modalidades (directa, bipolar y sobre apoyo).

La información procedente de los núcleos recuperados en el sitio Loma Ruiz 1 permite inferir que habría habido prueba de materias primas en una variedad de rocas locales más amplia que la representada en los instrumentos terminados. La forma de inicio del débitage más representado en el sitio es la técnica bipolar, aunque la misma no continúa siendo utilizada más allá de la prueba de materia prima sobre rocas locales y areales, principalmente de tamaño pequeño. Sobre rocas extraareales la reducción bipolar es un último gesto tendiente a maximizar la explotación de la materia prima (ver Figura 6.1.E). El grado de débitage más avanzado ocurre principalmente en núcleos (centrípetos y faciales) sobre rodados de tamaño grande y en núcleos sobre otros tipos de soportes de tamaño mediano, tanto en materias primas areales como alóctonas (ver Figuras 6.1.A y D; Figura 6.2.A).

\section{Desechos: materias primas, tamaños y técnicas de talla}

Dentro de esta categoría artefactual general $(n=501)$, el $35,53 \%(n=178)$ son lascas producto de actividades de retoque, el $31,34 \%(n=157)$ son débris de talla, el $12,57 \%(n=63)$ son lascas indeterminadas, el 10,77\% $(n=54)$ son lascas de débitage, el 6,98\% ( $n=35)$ son lascas de façonnage, el 2,59\% $(n=13)$ son lascas de descortezamiento y, finalmente, el 0,2 \% es un desecho térmico. Las materias primas más representadas son las calcedonias locales y/o areales con el $23,35 \%(n=117)$, las rocas silíceas con el $19,56 \%(n=98)$, el basalto o andesita con el $17,78 \%(n=89)$ y la ortocuarcita de Tandilia con el $12,57 \%(n=63)$. La dacita, la calcedonia translúcida, la metacuarcita de Ventania, las rocas indeterminadas, la tufita, la arenisca indeterminada, la riolita, la arenisca rionegrense y una posible obsidiana también están presentes, pero en frecuencias menores (Tabla 4). En cuanto al tamaño de los desechos, se destaca el rango entre los $11-20 \mathrm{~mm}$ con el $41 \%$ en todas las materias primas.

Todas las lascas de inicio de la talla son consecuencia de la aplicación de la percusión dura bipolar. Entre las lascas 


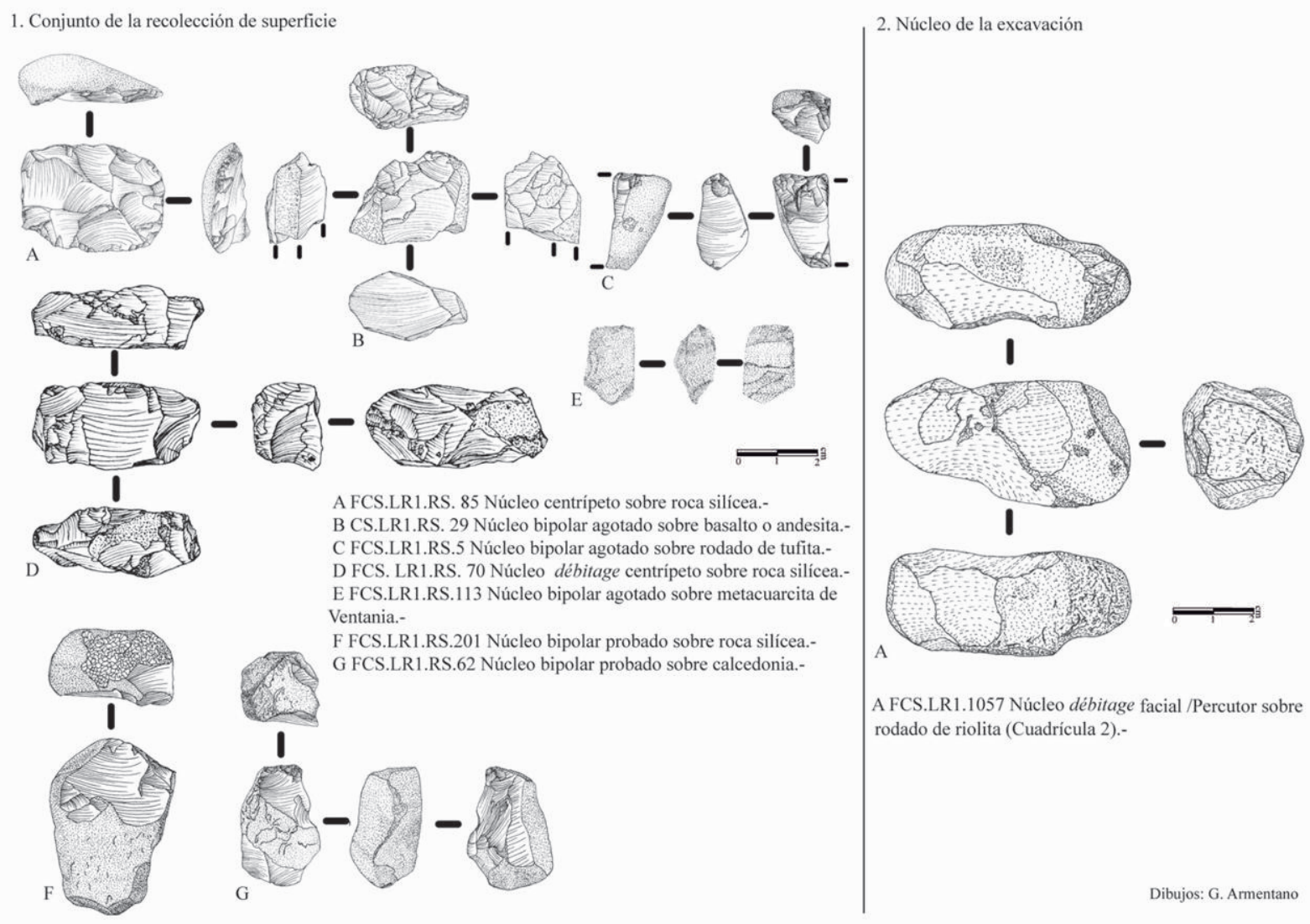

Figura 6.- Núcleos Figure 6.- Cores

\begin{tabular}{|c|c|c|c|c|c|c|c|c|c|c|c|c|c|c|c|}
\hline Tipos de lascas & 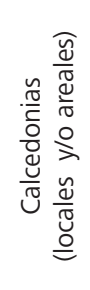 & 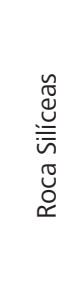 & $\begin{array}{l}\frac{0}{5} \\
\frac{5}{0} \\
\frac{0}{0} \\
\frac{5}{0} \\
\frac{9}{0} \\
\frac{ \pm}{0} \\
0 \\
0\end{array}$ & 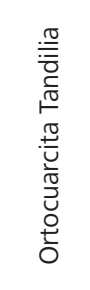 & 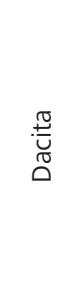 & 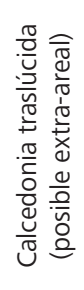 & 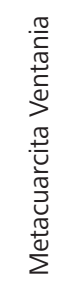 & 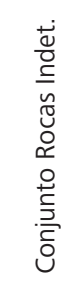 & $\underset{F}{\stackrel{0}{5}}$ & 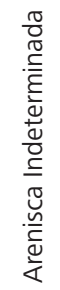 & $\frac{\frac{\pi}{\frac{\pi}{0}}}{\frac{0}{18}}$ & 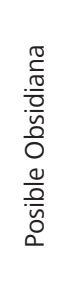 & 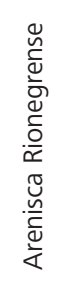 & $\underset{\vdash}{\stackrel{\overrightarrow{5}}{\circ}}$ & $\%$ \\
\hline Lascas de retoque & 55 & 49 & 21 & 15 & 12 & 23 & 3 & - & - & - & - & - & - & 178 & 35,53 \\
\hline Débris de talla & 23 & 25 & 28 & 22 & 11 & - & 11 & 19 & 5 & 9 & 3 & - & 1 & 157 & 31,34 \\
\hline $\begin{array}{l}\text { Lascas } \\
\text { Indeterminadas }\end{array}$ & 17 & 5 & 19 & 12 & 3 & - & 1 & 2 & 2 & - & - & 2 & - & 63 & 12,57 \\
\hline Lascas de débitage & 14 & 14 & 12 & 4 & 4 & - & 2 & - & 2 & - & 2 & - & - & 54 & 10,77 \\
\hline Lascas de façonnage & 4 & 4 & 5 & 10 & 1 & 4 & 6 & 1 & - & - & - & - & - & 35 & 6,98 \\
\hline $\begin{array}{l}\text { Lascas de } \\
\text { descortezamiento }\end{array}$ & 3 & 1 & 4 & - & 2 & - & - & - & 3 & - & - & - & - & 13 & 2,59 \\
\hline Desechos térmicos & 1 & - & - & - & - & - & - & - & - & - & - & - & - & 1 & 0,2 \\
\hline TOTAL & 117 & 98 & 89 & 63 & 33 & 27 & 23 & 22 & 12 & 9 & 5 & 2 & 1 & 501 & 100 \\
\hline$\%$ & 23,35 & 19,56 & 17,78 & 12,57 & 6,59 & 5,38 & 4,59 & 4,39 & 2,4 & 1,8 & 1 & 0,4 & 0,2 & 100 & \\
\hline
\end{tabular}

Tabla 4. Categorías de lascas y materias primas de superficie y estratigrafía.

Table 4. Flakes categories and raw materials recovered from surface and stratigraphic assemblages.

de débitage $(n=54)$, el $77,77 \%(n=42)$ son resultado de la talla bipolar, en el $12,96 \%(n=7)$ no se pudo determinar el modo de extracción, en el 9,25\% $(n=5)$ se extrajeron por medio de la percusión directa dura y el $7,40 \%(n=4)$ restante es consecuencia de la percusión directa blanda. Las lascas producto de actividades del façonnage de instrumentos $(n=35)$, en el $65,71 \%(n=23)$ son el resultado de la percusión directa blanda y en el $25,85 \%(n=8)$ el 
modo de extracción es indeterminado. Finalmente, entre las lascas de retoque $(n=178)$, el $17,41 \%(n=31)$ fueron extraídas por medio de la presión.

En síntesis, en la categoría de desechos, las materias primas más frecuentes en todos los tipos de desechos son las calcedonias locales o areales, las rocas silíceas y el basalto o andesita (Tabla 4). Las etapas mejor representadas de la cadena operativa son las etapas intermedias y finales, es decir las que corresponden a la regularización de los soportes y confección de instrumentos asociadas a los modos de percusión directa (dura y blanda) y la presión. Por su parte, los desechos de las primeras etapas de la reducción que se asocian a la talla bipolar de núcleos sobre rodados de tamaño pequeño son poco productivos, si se tiene en cuenta la cantidad de soportes utilizados a posteriori de su obtención para la confección de instrumentos.

\section{Cadenas y esquema operativo}

En base a la reconstrucción de las chaînes opératoires de cada una de las materias primas representadas en el sitio (Figura 7), queda claro que hay tres rangos de distancias involucrados en la adquisición de materias primas: local, areal y extra-areal. El modo de gestión de las materias primas se relaciona con la forma de presentación, la distancia potencial a las fuentes, el objetivo final de la cadena operativa, la función y el lugar de utilización de los instrumentos.

En primer lugar, los rodados de tamaño pequeño (elípticos en su mayoría) que pueden ser considerados locales (disponibles en las inmediaciones) habrían sido tallados íntegramente en el sitio (en todas las materias primas). El empleo del débitage bipolar mediante la percusión dura sobre yunque sin preparación previa del núcleo, la producción de soportes longilineos sobre los que se detectó una escasa transformación mediante el retoque y la sistemática presencia de rastros complementarios sobre los mismos, sugieren una producción de artefactos poco elaborados, de rápida utilización, desgaste y abandono en el sitio (Figura 7 A). En otras palabras, todas las etapas de esta chaîne opératoire se desarrollaron dentro o en los alrededores inmediatos al sitio, empleando materias primas disponibles localmente. Su realización no implicaría necesariamente, dada la evidencia recuperada, cortes espacio-temporales de la chaîne opératoire. La intención de la producción respondería a una necesidad puntual, coyuntural.

En segundo lugar, las materias primas areales (tamaños medianos y grandes que implican más tiempo de búsqueda), están representadas por los mismos tipos de rocas que las locales. Sin embargo, se distinguen de las anteriores por su mayor tamaño (no presente en los alrededores inmediatos del sitio), una tendencia hacia la mejor calidad y por su tratamiento vinculado con el débitage centrípeto. Los tamaños requeridos como soportes de dichos núcleos centrípetos no concuerdan con los tamaños de los desechos de inicio de la talla, mediante la talla bipolar. En consecuencia, la explotación de las rocas areales no se habría iniciado en el sitio. Solo se encuentran las etapas de producción avanzada de soportes y confección de instrumentos. La mayoría de los instrumentos recuperados en el sitio están confeccionados a partir de esta chaîne opératoire, lo que sugiere que se trata de la producción principal llevada a cabo en el sitio (Figura 7 B). Paralelamente, no se han recuperado los núcleos agotados de estas materias primas, por lo que posiblemente hayan sido traslados fuera del sitio. En este caso, hay claramente una planificación de las actividades y momentos de ruptura espacio-temporal de la chaîne opératoire. El primero, corresponde a la obtención y descortezamiento de la materia prima que ocurre fuera del sitio, dentro del área de estudio. En el segundo momento, correspondiente a la producción de soportes e instrumentos sobre estas materias primas en el sitio, la intencionalidad de la producción responde a una necesidad prevista con anticipación y, posiblemente también a la planificación de actividades posteriores (e.g.; traslado de núcleos fuera del sitio). Esta chaîne opératoire da cuenta de una estrategia tecnológica diferente, desarrollada en un circuito de circulación más amplio.

En tercer lugar, entre las rocas extra-areales la estrategia de gestión empleada es similar en todas las materias primas -rocas cuarcíticas y calcedonia traslúcida (Figura 7 C). Sendos tipos de rocas ingresaron al sitio ya sin corteza y como productos de un débitage centrípeto avanzado o façonnage (e.g.; lascas). Posiblemente, en el sitio se habrían confeccionado instrumentos mediante retoque. Aunque solo se recuperó un instrumento terminado de ortocuarcita de Tandilia (raclette, Figura 4.1.C y Figura 8) hay lascas de retoque que confirman esta interpretación. También se propone que, posiblemente se hayan confeccionado instrumentos bifaciales (¿puntas de proyectil?) sobre la calcedonia traslúcida, ya que se recuperaron lascas de façonnage sobre dicha materia prima. Finalmente, hay evidencias de posible reciclado de núcleos en pièces esquillée y de maximización de la explotación a través de la talla bipolar. Este modo de gestión de estas materias primas sugiere una estrategia de conservación de las mismas, ya sea por su calidad (e.g.; calcedonia traslúcida) o por la forma de adquisición. En este sentido, se propone que, posiblemente los artefactos de materias primas extra-areales hayan sido obtenidos mediante contactos puntuales entre individuos y/o grupos (Armentano 2012). En este caso, las rupturas de la chaîne opératoire implican no solo planificación de las actividades y cortes espacio-temporales sino también la interacción entre grupos.

\section{Discusión}

Sobre la base de distintas líneas de evidencia (e.g.; análisis 


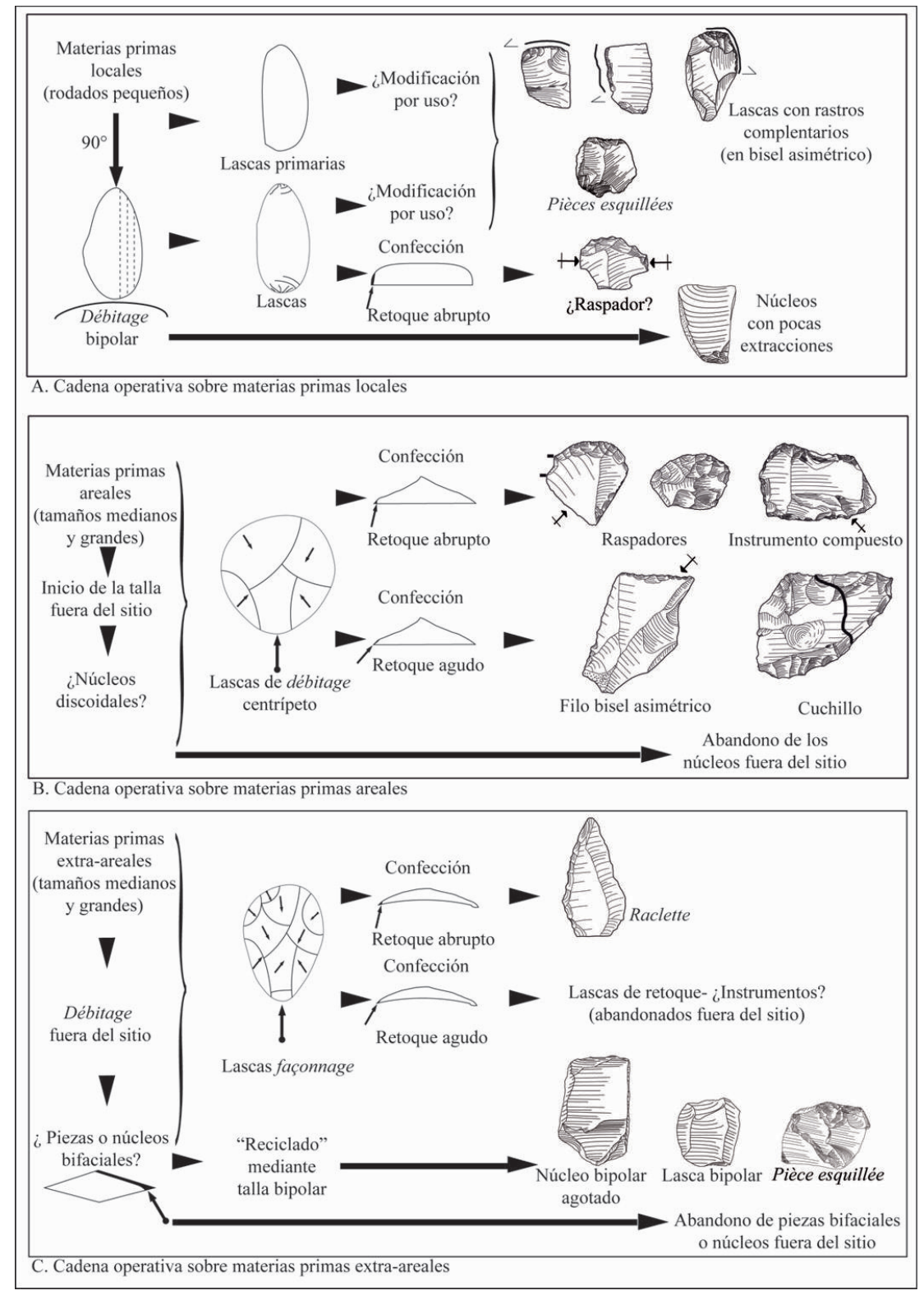

Figura 7.- Chaînes opératoires presentes en el sitio Figure 7.- Recorded Chaînes opératoires at the site disponibles localmente, ubicados en los alrededores inmediatos del mismo y que fueron explotados bipolarmente. Los grupos de cazadores-recolectores que se instalaron en Loma Ruiz 1 habrían llegado al sitio con al menos una cierta cantidad de núcleos ya descortezados o soportes listos para la talla, los que fueron complementados con una producción circunstancial in situ sobre materias primas locales. En este sentido, es remarcable también que la mayoría de los núcleos abandonados en el sitio corresponden a rodados locales. En consecuencia, se estima que los núcleos sobre rodados areales de mayores dimensiones podrían haber sido trasladados fuera del sitio.

Otro indicador de la duración breve de las ocupaciones procede del análisis de los materiales de molienda. Una fuente potencial de aprovisionamiento de materia prima para estos instrumentos (arenisca) se encuentra cercana al sitio (ca. $10 \mathrm{~km}$ ); no obstante, no hay un volumen importante de las mismas, ni evidencias de confección de artefactos en el sitio. La información no sugiere un equipamiento de este último (site furniture). La información procedente del conjunto artefactual lítico indica la presencia de por lo menos dos tipos de producción, una de arqueofaunas, de tecnología cerámica, etc.) Loma Ruiz 1 fue interpretado como un sitio de actividades residenciales, domésticas y culinarias, ocupado a través de estadías breves, asociadas a reocupaciones, durante parte del Holoceno tardío inicial (ca. 1900-1600 años AP) (Alcaráz 2012; Armentano 2012; Martínez y Martínez 2011; Stoessel 2012). En tal sentido, un primer indicio de la posible duración breve de las ocupaciones es la falta de evidencias de traslado de roca extra-areal hacia el sitio para el inicio de la talla en el mismo. Los artefactos tallados fueron confeccionados sobre soportes extraídos de rodados considerados areales (medianos y grandes) o de materias primas extra-areales, sobre los que hay escasas evidencias de inicio de talla in situ. La producción que se habría llevado a cabo íntegramente en el sitio fue la que se desarrolló sobre rodados planificada con anterioridad al momento de utilización de los instrumentos (rocas areales y extra-areales) y otra coyuntural y ad hoc realizada en el contexto de uso de los mismos (rocas locales). La primera, implica el traslado de rocas de media distancia y un posible intercambio a larga distancia, en tanto que la segunda puede ser resuelta en los alrededores inmediatos del sitio (Armentano 2012).

El instrumental lítico presenta una escasa variabilidad tipológica como raspadores, filos en bisel asimétrico, cuchillo, raclette e instrumentos compuestos (Tabla 3). Las lascas con rastros complementarios presentan filos (o bordes con rastros) morfológicamente similares a los grupos tipológicos relevados en los instrumentos simples. La evidencia procedente de los instrumentos señala la importancia de la producción unifacial. 


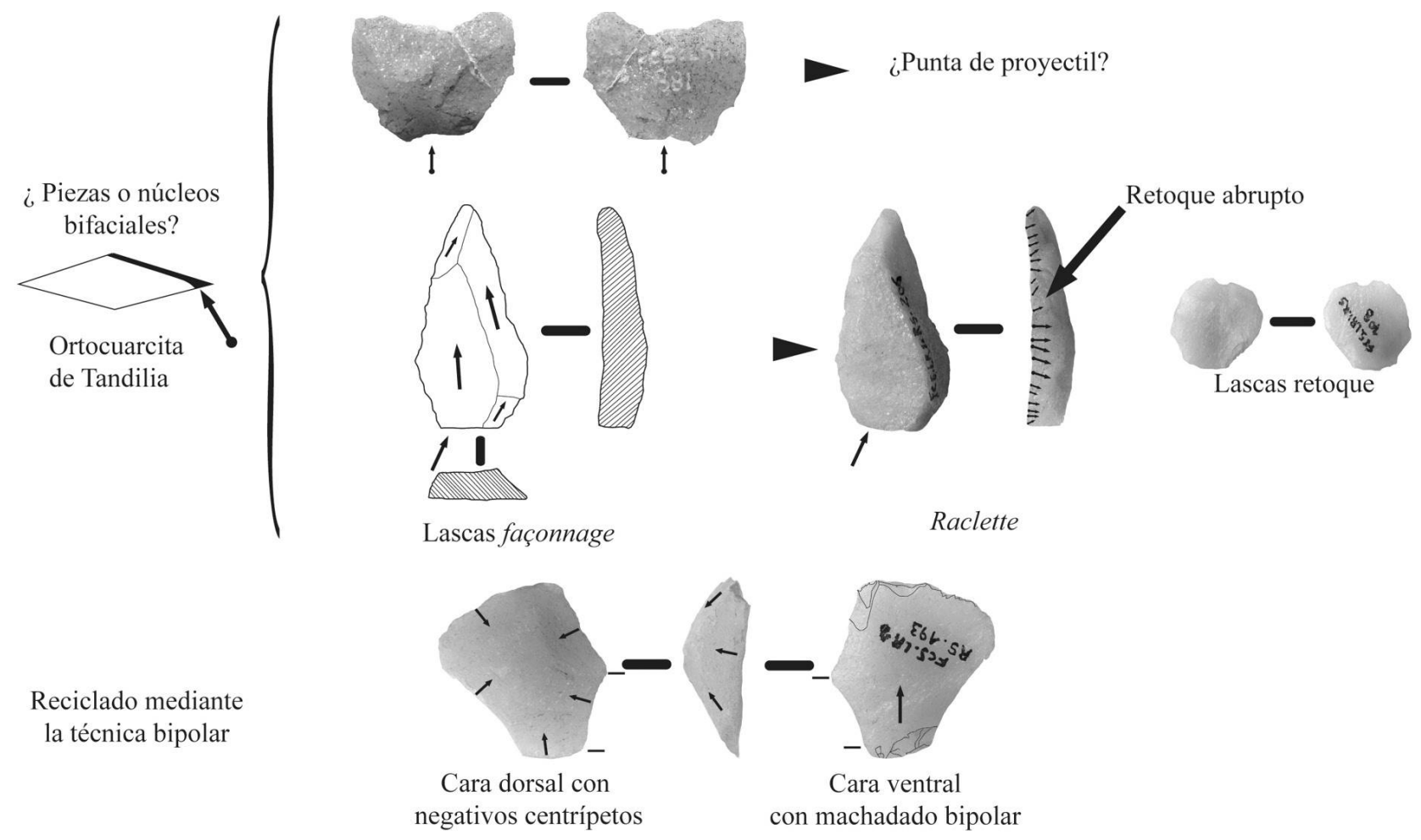

Figura 8.- Artefactos sobre ortocuarcita del Sistema Serrano de Tandilia (materia prima extra-areal)

Figure 8. - Artifacts made on ortoquartzite from Tandilia mountain ranges (extra-areal lithic raw material).

La información procedente del estado, tamaños y tipos de soporte empleados indica que algunos instrumentos ingresaron en un estado avanzado de confección o ya terminados, y que algunos fueron reavivados en el sitio. El análisis de los desechos indica la presencia de otras actividades de talla cuyos productos finales (los instrumentos) no están presentes en el sitio. En este sentido, es notoria la presencia de lascas de façonnage sobre materias primas locales, areales y extra-areales (Tabla 4) y la ausencia de piezas bifaciales. Es decir, la evidencia indica actividades de confección de otra clase de instrumentos (instrumentos bifaciales o bifaces) que fueron transportados fuera del sitio (ver Flegenheimer 2001). Las tendencias aquí delineadas coinciden en algunos puntos con la propuesta de Pèrles (1991) referida a la producción independiente de soportes diferenciados para cada clase de instrumentos, según las exigencias y limitantes de cada materia prima. En Loma Ruiz 1 las diferencias no conciernen solamente al tipo de productos sino también a las técnicas puestas en obra (débitage centrípeto o bipolar). Según Pèrles las diferentes chaînes opératoires implican distintos grados de exigencia de savoir-faire ${ }^{6}$ y calidad de la producción. La misma puede estar repartida entre distintos talladores al interior de un mismo grupo. No obstante, la complejidad técnica de las chaînes opératoires reconstruidas en Loma Ruiz 1 es, en todos los casos, muy simple y no pudieron detectarse claros indicios de niveles de savoir-faire diferentes que permitan reconocer distintos productores. Sin embargo, sí pudo identificarse la diferencia entre las chaînes opératoires en diferentes lugares y momentos de producción. La evidencia procedente de las rocas extraareales estaría indicando una circulación de artefactos, antes que de materias primas (ver debajo).

\section{Conclusiones}

La evidencia provista por el sitio Loma Ruiz 1 contribuye a entender las tendencias tecnológicas planteadas para el área (Armentano 2004, 2007, 2012), dentro del modelo arqueológico y conductual propuesto para la misma (Martínez 2008-2009). Este modelo propone una diferenciación entre los sitios de las Ocupaciones Iniciales (ca. 3000-1000 años AP.; Holoceno tardío inicial) y las Ocupaciones Finales (ca. 1000-250 años AP.; Holoceno tardío final), en distintos aspectos de la organización de las sociedades cazadoras-recolectoras que habitaron el área (e.g.; subsistencia, asentamiento, movilidad, prácticas mortuorias, etc.; ver Alcaráz 2012; Martínez 2008-2009; Martínez et al. 2012 a; Stoessel 2012). A partir del estudio de los materiales líticos, Armentano (2012) propuso la existencia de un patrón tecnológico común para todo el Holoceno tardío que involucra las formas de gestión de las materias primas locales y areales (e.g.; tratamiento volumétrico similar de todos los rodados), las formas de confección (e.g.; mismos métodos de débitage empleados con diferente intensidad según el bloque temporal considerado), el criterio de selección de los soportes (e.g.; variación del espesor en función del instrumento buscado) y las clases de instrumentos realizados (Armentano 2012). No obstante, la existencia de este patrón para el Holoceno 
tardío, Armentano (2012) destaca que hacia la parte final de este periodo (ca. 1000-250 años AP) se observa una menor frecuencia de determinados métodos de débitage, donde el débitage centrípeto se constituye en la chaînes opératoires principal, casi exclusiva, de los sitios de las Ocupaciones Finales. Para este lapso, la producción artefactual se concentra particularmente en dos clases de instrumentos, las puntas de proyectil y los raspadores, en tanto se explotan mayoritariamente dos materias primas, las rocas silíceas y calcedonias (Armentano 2012). Por el contrario, para el Holoceno tardío inicial - lapso cronológico donde su ubican las ocupaciones de Loma Ruiz 1 - se observa una mayor diversidad de modalidades de débitage como el bipolar, unipolar corto, en rodajas y faciales (a excepción de que existan limitantes físicas que solo permitan el empleo de la técnica bipolar). Esta variabilidad de métodos de debitage se emplea para la producción de variados soportes de instrumentos y no se registra una clara predominancia de uno en particular. Para este periodo, se observa un mayor empleo del façonnage directo sobre rodados y un rango de variación mayor en el espesor de los soportes. Es notable también la mayor variabilidad tipológica registrada en este periodo (Armentano 2012). En general, algunas de las características tecnológicas del Holoceno tardío inicial se presentan en Loma Ruiz 1 y son compartidas con otros sitios del área (e.g.; sitios El Caldén y El Puma; Armentano 2012; Martínez et al. 2012 b). En Loma Ruiz 1, las rocas extra-areales presentes son cuarcitas (ortocuarcita y metacuarcita) y, posiblemente, la calcedonia traslúcida. Para este lapso, los datos procedentes de los instrumentos y preformas (e.g.; raclettes, raederas dobles convegentes, puntas de proyectil) confeccionados sobre rocas extraareales sugieren que habría habido una obtención de instrumentos terminados (o preformas), tal como sucede en otras localidades del área, como el Caldén (Armentano 2010). La presencia de las cuarcitas y de las calcedonias translúcidas en los sitios de esta área de transición Pampeano-Patagónica oriental indicaría contactos entre individuos y/o grupos de áreas vecinas como la subregión Pampa Humeda y, posiblemente, Norpatatagonia.

Las conclusiones aquí vertidas son el resultado del interés en la caracterización de la tecnología lítica de los grupos que habitaron la zona de transición pampeanopatagónica oriental durante el Holoceno tardío. Los resultados alcanzados se basan en un enfoque teórico metodológico fundamentalmente ligado a la escuela francesa, cuya aplicación es novedosa en el área y enriquece las interpretaciones del registro lítico del curso inferior del río Colorado.

Olavarría, 7 de agosto 2012.

\section{Agradecimientos}

A la Dra. Paula Barros por las sugerencias vertidas sobre este manuscrito. Las investigaciones fueron financiadas por Wenner Gren Foundation for Anthropological Research (Grant Nro. 6780), Fundación Antorchas (Proyecto 14022-2) y ANPCYT (PICT N²64). Agradecemos al INCUAPA-CONICET (FACSO- UNCPBA).

\section{Notas}

1 Débitage y façonnage: El primer término "(...) se emplea solamente para los productos obtenidos intencionalmente por percusión y/o presión (...) El débitage divide la materia prima en dos categorías, de objetos complementarios: los núcleos y los productos del débitage" (Inizan et al. 1995:59, t.p.). Por su parte el façonnage "Es una operación de talla que tiene por finalidad la fabricación de un objeto, esculpiendo la masa de materia prima seleccionada, según la forma deseada. Esta operación presenta en general, una fase de esbozamiento, y después de finalización, y puede necesitar varias técnicas" (Inizan et al. 1995:59, t.p.). El término façonnage, se aplica a la transformación de la forma original del soporte únicamente de manera bifacial, no puede ser traducido por el término formatización empleado comúnmente en la arqueología argentina. Para la descripción de la realización de instrumentos unifaciales se utiliza el término confección.

2 "La técnica es al mismo tiempo el gesto y el instrumento, organizados en una cadena a través de una verdadera sintaxis, que le brindan a las series operatorias su fijeza y su flexibilidad" (Leroi-Gourhan, A. [1964] 2004, t.p). Dentro de esta definición el gesto es intencional y representativo, dado que el mismo es aprendido culturalmente. La sintaxis es la ley, es la que establece que la serie de operaciones se produzcan dentro de un determinado orden, es la organización. La fijeza es el objetivo, la norma, detrás de esta se encuentra el objeto buscado.

${ }^{3}$ Correspondencia entre dos fragmentos de un mismo artefacto fracturado no intencionalmente (ver Armentano 2012).

${ }^{4}$ El desplazamiento lateral no pudo ser estimado por la ausencia de medidas tridimensionales en una de las piezas. No obstante, las cuadrículas son contiguas, lo que permite estimar una distancia lateral máxima de $4 \mathrm{~m}$.

${ }^{5}$ Pièce esquillée y bâtonnets: "Pieza generalmente rectangular o cuadrada, a veces de dimensiones muy pequeñas, que presenta en sus dos extremos (rara vez en uno solo), astillamientos frecuentemente bifaciales, causados por una percusión violenta. (...). Se pueden distinguir grosso modo, tres estadios de utilización:

$1^{\circ}$ Estadio: extremidades astilladas, no hay evidencias de lascados invasivos sobre la pieza, caras superior $e$ inferior en gran parte intactas.

$2^{\circ}$ Estadio: (...) imposible distinguir las caras.

$3^{\circ}$ Estadio: ruptura de la pieza en varios fragmentos: 
pequeños "bâtonnets" de sección triangular o cuadrangular que no presentan talón (este se encuentra reducido a un punto)" (Tixier 1963:146,147, t.p).

6 "Saber qué es necesario hacer no significa saber hacer. La pericia o habilidad práctica o savoirfaire motor (estimación de la energía necesaria, cálculo de la incidencia del golpe, adaptación del movimiento y coordinación) necesita no solamente de las representaciones metales de las formas y las secuencias, sino también de la percepción y análisis de la situación, de la apreciación de parámetros geométricos. La situación observada es puesta en referencia con el modelo ideal (savoir-faire ideacional). (...)También ocurre una evocación y selección de las modalidades adecuadas (registro de conocimientos) dentro de un grado de circunstancias siempre variables. Luego (...) se adopta la modalidad mejor adaptada y lo preferida entre el espacio de las posibilidades limitadas por las limitaciones técnicas y su apreciación construida sobre las experiencias anteriores" (Pelegrin 1995:34, t.p).

\section{Bibliografía}

Alcaráz, A. 2012. "Análisis zooarqueológico y tafonómico de restos óseos de pequeños vertebrados de sitios del curso inferior del río Colorado (Pcia. de Buenos Aires) durante el Holoceno tardío: Aportes para el conocimiento de la subsistencia y procesos de formación". Facultad de Ciencias Sociales, Universidad Nacional del Centro de la Provincia de Buenos Aires, Argentina, 206 páginas. Tesis de grado. FACSO-UNICEN, Olavarría.

Armentano, G.2004. “Organización de la Tecnología Lítica en el Valle Inferior del río Colorado (Partidos de Patagones y Villarino, Pcia. de Buenos Aires)". Facultad de Ciencias Sociales, Universidad Nacional del Centro de la Provincia de Buenos Aires, Argentina, 267 páginas. Tesis de grado. FACSO-UNICEN. Olavarría.

Armentano, G. 2007. Aplicación de la metodología de Cadenas Operativas al material lítico del curso inferior del Río Colorado. Bayón, C., A. Pupio, M. I. González, $\mathrm{N}$. Flegenheimer y M. Frère editores, Arqueología en las Pampas, pp. 161-178. Sociedad Argentina de Antropología, Buenos Aires.

Armentano, G. 2012. "Arqueología del curso inferior del Río Colorado. Estudio tecnológico de las colecciones líticas de Norpatagonia Oriental durante el Holoceno tardío. Departamentos de Villarino y Patagones, Provincia de Buenos Aires. Argentina". Universidad Nacional del Centro de la Provincia de Buenos Aires, Argentina y Université de Paris Ouest Nanterre- La Défense, Francia, 543 páginas. Tesis de postgrado en cotutela. Olavarría y Nanterre. FACSO-UNICEN.

Barberena, R., A. Hajduk, A. Gil, G. Neme, V. Durán, M.
Glascock, M. Giesso, K. Borrazzo, M. Pompei, M. Salgán, V. Cortegoso, G. Villarosa y A. Rughinia. 2011. Obsidian in the south-central Andes: geological, geochemical, and archaeological assessment of north Patagonian sources (Argentina, South America). Quaternary International 245(1): 25-36.

Bayón, C., N. Flegenheimer, M. Valente y A. Pupio. 1999. Dime cómo eres y te diré de dónde vienes: La procedencia de rocas cuarcíticas en la región pampeana. Relaciones de la Sociedad Argentina de Antropología XXIV: 187-235.

Bayón, C., G. Martínez, G. Armentano y C. Scabuzzo. 2004. Arqueología del valle inferior del río Colorado: el sitio La Primavera. Intersecciones en Antropología 5:39-53.

Berón, M. 2004. “Dinámica poblacional y estrategias de subsistencia de poblaciones prehispánicas de la cuenca Atuel-Salado-Chadileuvú-Curacó, Provincia de La Pampa." Facultad de Filosofía y Letras, Universidad Nacional de Buenos Aires, Argentina, 454 páginas. Tesis de postgrado. FFyL-UBA. Buenos Aires.

Bonomo, M.y L. Prates. 2006. La explotación de depósitos secundarios de rodados en el curso medio del Río Negro y el litoral Marítimo Pampeano. Manuscrito, 18 páginas. Museo de Ciencias Naturales. División Arqueología, La Plata.

Cardillo, M. y F. Scartascini. 2007. Tendencias observadas en las estrategias de explotación de recursos líticos en el Golfo San Matías. Provincia de Río Negro. Argentina. Arqueología de Fuego-Patagonia. Levantando piedras, desenterrando huesos... y develando arcanos. F. Morello, M. Martinic, A. Prieto y G. Bahamonde editores, pp. 117127. Editorial CEQUA. Punta Arenas.

Carrera Aizpitarte, M. 2006 "Estrategias de aprovisionamiento lítico en el área Centro-Oeste de la Provincia de La Pampa". Facultad de Ciencias Sociales, Universidad Nacional del Centro de la Provincia de Buenos Aires, Argentina, 267 páginas. Tesis de grado. FACSOUNICEN.Olavarría.

Fidalgo, F. y J. Riggi. 1970. Consideraciones geomórficas y sedimentológicas sobre Rodados Patagónicos. Revista de la Asociación Argentina de Geología XXV (4): 430-443.

Flegenheimer, N. 2001. Biface transport in the Pampean Region, Argentina. Current Research in the Pleistocene Vol. 18: 21-22.

Flegenheimer, N. y C. Bayón 2002. Cómo, cuándo y dónde? Estrategias de abastecimiento lítico en la Pampa Bonaerense. Mazzanti, D., M. Berón y F. Oliva editores, Del mar a los salitrales. Diez mil años de Historia Pampeana 
en el Umbral del Tercer Milenio, pp. 231-241. Sociedad Argentina de Antropología. Mar del Plata.

Hermo, D. 2008. Rocas como símbolos: la selección de materias primas para puntas de proyectil en ambientes mesetarios de Patagonia. Intersecciones en Antropología 3:19-324.

Inizan, M. L., M. Reudon, H. Rocheet J. Tixier (editores).1995. Tecnologie de la pierre taillée. Éditions. Vol.4. Meudon Cedex France.

Leroi-Gourhan, A. [1964] 2004. Le geste et la parole I. Technique et langage. Albin Michel ed. Sciences d'aujourd'hui, Paris.

Martínez, G. 2004. Resultados preliminares de las investigaciones arqueológicas realizadas en el curso Inferior del río Colorado (Partidos de Villarino y Patagones, provincia de Buenos Aires). G. Martínez, M. A. Gutiérrez, R. Curtoni, M. Berón y P. E. Madrid editores, Aproximaciones Contemporáneas a la Arqueología Pampeana. Perspectivas teóricas, metodológicas, analíticas y casos de estudio, pp. 275-292. Facultad de Ciencias Sociales. Universidad Nacional del Centro de la Provincia de Buenos Aires, Olavarría.

Martínez, G. 2008-2009. Arqueología del curso inferior del río Colorado: estado actual del conocimiento e implicaciones para la dinámica poblacional de cazadoresrecolectores pampeano-patagónicos. Cazadores recolectores del cono sur. Revista de arqueología 3: 73-94.

Martínez, G.; C. Landini; L. Stoessel y A. Bonetti. 2004. Estratigrafía, cronología, análisis de artefactos líticos, cerámicos y de restos faunísticos del sitio arqueológico Loma Ruiz 1 (Pdo. de Villarino, Pcia. de Buenos Aires). Libro de resúmenes XV Congreso Nacional de Arqueología Argentina, p. 354. Río Cuarto

Martínez, G. y G. A. Martínez. 2011. Late Holocene environmental dynamics in fluvial and aeolian depositional settings: Archaeological record variability at the lower basin of the Colorado river (Argentina). Quaternary International 245(1): 89-102.

Martínez, G.; G. Flensborg y P. Bayala. 2012a. Human corpse manipulation and the body as symbol: A case study from the Eastern Pampa-Patagonia transition (Argentina) during the Final Late Holocene. Journal of Anthropological Archaeology 31: 215-226.

Martínez, G.; Martínez, G.A.; Santos, F.; Stoessel, L.; Alcaráz, A. O.; Flensborg, G.; Bayala, P. y G. Armentano. 2012b. Primeros resultados de la localidad arqueológica "El Puma" (curso inferior del Río Colorado, Pcia. de Buenos Aires). Comechingonia 16: 185-205.
Martínez, G., P. Madrid y A. Bonetti. 2011. Análisis tecnomorfológico de la alfarería del sitio Loma Ruíz 1 (curso inferior del río Colorado, provincia de Buenos Aires). VI Congreso de Arqueología de la región pampeana argentina. Revista del Museo de La Plata 12 (86): 47-48.

Matarrese, A. 2009. Artefactos picados y/o abradidos del sitio arqueológico Loma Ruiz (Pdo. Villarino, provincia de Buenos Aires). Informe Manuscrito, 2 páginas. Museo de Ciencias Naturales. División Arqueología, La Plata.

Miotti, L., M. Saleme, D. Hermo, L. Magnin y J. Rabassa. 2004. Yamnago 130 años después: otro lenguaje para la misma región. M. T. Civalero, P. M. Fernández y A. G. Guráieb editores, Contra viento y marea. Arqueología de Patagonia, pp. 775-796, Instituto Nacional de Antropología y Pensamiento Latinoamericano, Buenos Aires.

Pelegrin, J.1995. Technologie Lithique: Le Châtelperronien de Roc-de-Combe (Lot) et de La Côte (Dordogne). Centre National de Recherche Scientifique ed. Cahier du Quaternaire 20, Paris.

Pèrles, C.1991. Économie des matières premières et économie du débitage: deux conceptions opposées? Association pour la promotion et la diffusion des connaissances archéologiques editor, 25 ans d'études technologiques en préhistoire: bilan et perspectives. $X I^{e}$ Rencontres Internationales d'Archéologie et Histoire d'Antibes, pp. 35-45. APDCA Éditions, Juan-les Pins.

Prates, L. 2008. Los indígenas del río Negro. Un enfoque arqueológico. 323 páginas. Sociedad Argentina de Antropología, Buenos Aires.

Stoessel, L. 2007. Análisis arqueofaunísticos de los sitios Loma Ruíz 1 y El Tigre (partidos de Villarino y Patagones, provincia de Buenos Aires). Aportes para el conocimiento de la subsistencia en el valle inferior del río Colorado durante el Holoceno tardío. Intersecciones en Antropología. 8: 235-251.

Stoessel, L. 2012. "Aportes para el conocimiento de la subsistencia de cazadores-recolectores en el Holoceno tardío". Facultad de Ciencias Sociales, Universidad Nacional del Centro de la Provincia de Buenos Aires, Argentina. 380 páginas. Tesis de postgrado. FACSOUNICEN. Olavarría.

Tixier, J. 1963. Typologie de l'épipaléolithique du Maghreb. Mémoires du Centre de recherches anthropologiques, préhistoriques et ethnographiques. 209 páginas. Arts et métiers graphiques, Paris.

Torres, L. 1922. Arqueología de la Península de San Blas (Provincia de Buenos Aires). Revista del Museo de La Plata XXVI: 473-532. 
Zavala, C. y R. Freije. 2001. On the understanding of Aeolian sequences stratigraphy: an exemple from Miocene-Pliocene deposits in Patagonia, Argentina.
Rivista Italiana di Paleontologia e Stratigrafia 107(2): 251-264. 